\title{
Magnetic resonance imaging assessment of degenerative cervical myelopathy: a review of structural changes and measurement techniques
}

\author{
Aria Nouri, MD, MSc, ${ }^{1,3}$ Allan R. Martin, MD, , ${ }^{1,3}$ David Mikulis, MD,, ${ }^{2,3}$ and \\ Michael G. Fehlings, MD, PhD, FRCSC 1,3 \\ Divisions of ${ }^{1}$ Neurosurgery and Spine Program and ${ }^{2}$ Brain Imaging \& Behaviour Systems, University of Toronto; and ${ }^{3}$ Toronto \\ Western Hospital, University Health Network, Toronto, Ontario, Canada
}

\begin{abstract}
Degenerative cervical myelopathy encompasses a spectrum of age-related structural changes of the cervical spine that result in static and dynamic injury to the spinal cord and collectively represent the most common cause of myelopathy in adults. Although cervical myelopathy is determined clinically, the diagnosis requires confirmation via imaging, and $M R I$ is the preferred modality. Because of the heterogeneity of the condition and evolution of MRI technology, multiple techniques have been developed over the years in an attempt to quantify the degree of baseline severity and potential for neurological recovery. In this review, these techniques are categorized anatomically into those that focus on bone, ligaments, discs, and the spinal cord. In addition, measurements for the cervical spine canal size and sagittal alignment are also described briefly. These tools have resulted collectively in the identification of numerous useful parameters. However, the development of multiple techniques for assessing the same feature, such as cord compression, has also resulted in a number of challenges, including introducing ambiguity in terms of which methods to use and hindering effective comparisons of analysis in the literature. In addition, newer techniques that use advanced MRI are emerging and providing exciting new tools for assessing the spinal cord in patients with degenerative cervical myelopathy.
\end{abstract}

http://thejns.org/doi/abs/10.3171/2016.3.FOCUS1667

KEY WORDS spine; cervical spondylotic myelopathy; stenosis; disc disease; method; diffusion tensor imaging; compressive myelopathy

$\mathrm{D}$ EGENERATIVE cervical myelopathy (DCM) encompasses a spectrum of age-related conditions of the cervical spine that result in progressive spinal cord impairment and significant physical and social disability ${ }^{77}$ (Fig. 1). With the advent of MRI, the ability to inspect the cervical anatomy meticulously has enabled clinicians and researchers to better understand the importance of imaging findings in patients with myelopathy. ${ }^{33,59,109,114,120}$ Indeed, there have been numerous studies that have demonstrated the utility of MRI factors, including for diagnosing patients, relating cord compression with baseline severity, and showing that signal changes of the spinal cord on T1- and T2-weighted imaging (T1WI and T2WI, respectively) have a modest ability to predict recovery after surgery. ${ }^{6,33,42,51,78,91,115,119}$ However, these studies have also pointed to a number of significant controversies and limitations in the utility of MRI. These controversies emanate partially from an inadequate understanding of the correlation between findings on MRI and the variable clinical presentations of DCM. According to recent research, advanced MRI techniques that measure aspects of spinal cord microstructure and function have the potential to address these issues by characterizing the degree of tissue damage and correlating it with neurological and functional disability.$^{59}$ However, correlating imaging findings with the clinical picture is also complicated by the increasingly wide-ranging set of measurement techniques that are used to evaluate pathological features on MRI. In

ABBREVIATIONS CR = compression ratio; CSA = cross-sectional area; $D C M=$ degenerative cervical myelopathy; $D T I=$ diffusion tensor imaging; $F A=$ fractional anisotropy; fMRI = functional MRI; IVD = intervertebral disc; JOA = Japanese Orthopaedic Association; $L F$ = ligamentum flavum; MCC = maximum canal compromise; mJOA = modified JOA; MRS = MR spectroscopy; MSCC = maximum spinal cord compression; MT = magnetization transfer; MTR = MT ratio; MWF = myelin water fraction; NAA = $\mathrm{N}$-acetyl aspartate; OPLL = ossification of the posterior longitudinal ligament; PLL = posterior longitudinal ligament; $\mathrm{ROI}=$ region of interest; $\mathrm{T} 1 \mathrm{WI}=\mathrm{T} 1$-weighted imaging; $\mathrm{T} 2 \mathrm{WI}=\mathrm{T} 2$-weighted imaging; $\mathrm{VB}=$ vertebral body.

SUBMITTED February 1, 2016. ACCEPTED March 22, 2016.

INCLUDE WHEN CITING DOI: 10.3171/2016.3.FOCUS1667. 
addition, there remain fundamental knowledge gaps surrounding the normal anatomy and natural history of cervical degeneration, as seen on MRI, that would be essential baseline indicators from which pathological findings can be identified objectively.

To begin to address these issues, in this review we discuss the normal anatomy of the cervical spine on MRI, pathological deviations from normal, MRI assessment techniques and their reliability, and emerging MRI techniques. This work is intended to serve collectively as a reference for spine care health professionals for the evaluation of DCM through MRI.

\section{Cervical Spine Anatomy and Structures Involved in DCM}

Detailed inspection of the cervical spine is usually performed by using conventional T1WI and T2WI on the axial and sagittal planes. The normal cervical spine appears lordotic and contains within it the spinal canal, which is bounded by the posterior longitudinal ligament (PLL) and vertebral bodies (VBs) anteriorly, the pedicles laterally, and the ligamentum flavum (LF) and lamina posteriorly. The canal size measured via MRI (typically T2WI) varies depending on the level assessed and decreases with age in both men and women. ${ }^{43,72}$ It was recently estimated that the anterior-posterior canal size on T2WI at the intervertebral discs (IVDs) is between 12.7 and $14.4 \mathrm{~mm}$ and between 11 and $13.6 \mathrm{~mm}$ in men in their 20s and 70s, respectively, and between 12.6 and $14.3 \mathrm{~mm}$ and between 10.8 and $13.5 \mathrm{~mm}$ in women in their 20s and 70s, respectively. ${ }^{43}$ The spinal cord cross-sectional area (CSA) depends on several factors including height, rostrocaudal level (greatest at C-4), and age; it peaks in the 3rd decade of life and then begins decreasing. ${ }^{38,43,100}$ However, the mean spinal cord CSA has varied from 75 to $90 \mathrm{~mm}^{2}$ between studies, which suggests that technical factors (e.g., acquisition techniques) or differences in demographics might affect this measurement substantially. ${ }^{38,43}$

Degenerative changes in the spine involve a host of specific structures, including the IVDs, VBs, spinal ligaments, and the uncovertebral and facet joints. ${ }^{77}$ The process begins with the degeneration and loss of the structural integrity of the IVDs and vertebral endplates. When it is severe, failure of the annulus fibrosus may result in disc bulging or herniation through the annulus into the spinal canal, causing compression of the neural elements. With a more gradual degenerative course, uneven forces exerted on the VBs result in VB restructuring, osteophyte formation, and irregularity of the facet joints, a process referred to as spondylosis. ${ }^{11,29}$ In the setting of significant degeneration, instability and spondylolisthesis may accompany these changes.

Aberrations of the spinal canal ligaments can include hypertrophy and ossification of the PLL and the LF. Although the term "hypertrophy" is used normally to indicate the enlargement of normal tissue, hypertrophy of the PLL has been defined as "hyperplasia of nonfibrous cartilage with strong metaplasia in the PLL in more than two intervertebral spaces, with capillary hyperplasia and infiltration of the connective tissue." ${ }^{37}$ Hypertrophy of

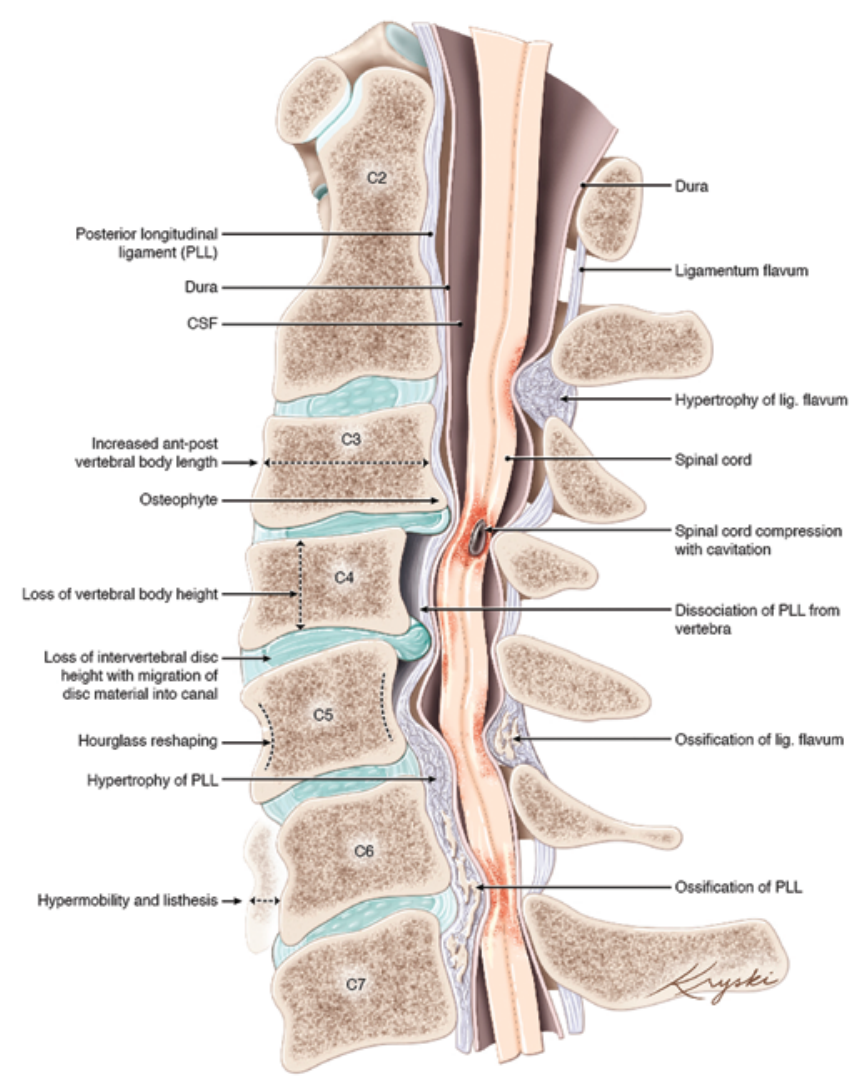

FIG. 1. Artistic depiction of the constellation of anatomical changes that can present in the cervical spine of patients with DCM. ant-post $=$ anterior-posterior; lig = ligamentum. Copyright Kryski Biomedia. Diana Kryski, Medical Illustrator. Published with permission.

the PLL has been suggested to precede ossification, and both can occur as a result of segmental stress and environmental and genetic factors. ${ }^{37,77}$ In addition, it has been suggested that hypertrophy of the PLL can arise as a reaction to nucleus pulposus protrusion. ${ }^{66}$ In terms of the LF, hypertrophy or buckling can occur as a result of other degenerative changes in the spine, including the loss of IVD height and hypertrophy of the facet joints, but genetic factors have also been postulated, particularly in relation to its ossification. ${ }^{47,48}$ In rare cases, ossification of the LF can also manifest concomitantly with ossification of the PLL, which has been referred to as "tandem ossification." ${ }^{86} \mathrm{An}$ even less frequent entity is calcification of the LF, which can be differentiated from ossification on the basis of histopathology. ${ }^{64}$ Table 1 summarizes pathological changes that can be appreciated with an MRI examination.

In the following section, the MRI characteristics of and methods for evaluating pathological changes of each anatomical structure involved in DCM are described.

\section{Disc Degeneration}

The IVD is an avascular structure that depends on diffusion of oxygen and nutrients from the VB endplates, a process that is impaired progressively with age and also with cigarette smoking. ${ }^{2}$ Disc degeneration occurs gradually and is extremely common in asymptomatic adults; $98 \%$ of healthy adults in their 20 s show early changes. ${ }^{61,75}$ 
TABLE 1. Degenerative features that may be evident on cervical MRI examination

\begin{tabular}{|c|c|}
\hline Feature & Description \\
\hline $\begin{array}{l}\text { Vertebral } \\
\text { bone } \\
\text { changes }\end{array}$ & $\begin{array}{l}\text { Decreased vertebral height } \\
\text { Increased anterior-posterior diameter } \\
\text { Osteophyte/bone spur formation } \\
\text { Hourglass reshaping } \\
\text { Modic changes of VBs } \\
\text { Type I: inflammatory changes (bone marrow edema); } \\
\text { decreased SI on T1WI, increased SI on T2WI* } \\
\text { Type II: local fatty replacement of bone marrow; } \\
\text { increased SI on T1WI, increased SI or no change } \\
\text { in SI on T2WI } \\
\text { Type III: reactive osteosclerosis; decreased SI on } \\
\text { T1WI, decreased SI on T2WI } \\
\text { Schmorl's node }\end{array}$ \\
\hline $\begin{array}{l}\text { IVD degen- } \\
\text { eration }\end{array}$ & $\begin{array}{l}\text { Reduced disc height } \\
\text { Disc bulging } \\
\text { Symmetric } \\
\text { Asymmetric } \\
\text { Disc herniation } \\
\text { Through annulus fibrosus but not PLL } \\
\text { Through annulus fibrosus \& PLL } \\
\text { Through annulus fibrosus, PLL, \& dura mater (rare) } \\
\text { Sequestration-herniated material no longer con- } \\
\text { tiguous w/ the disc } \\
\text { Variable SI dependent on water content \& calcification }\end{array}$ \\
\hline $\begin{array}{l}\text { PLL } \\
\text { changes }\end{array}$ & $\begin{array}{l}\text { Hypertrophy of the ligament } \\
\text { Ossification of the ligament } † \\
\text { Continuous (extending beyond 1 VB) } \\
\text { Segmental (not continuous) } \\
\text { Mixed (continuous \& segmental) } \\
\text { Circumscribed/nodular (located behind IVD) }\end{array}$ \\
\hline LF changes & $\begin{array}{l}\text { Hypertrophy } \\
\text { Ossification† } \\
\text { Calcification† }\end{array}$ \\
\hline $\begin{array}{l}\text { Other } \\
\text { structural } \\
\text { changes }\end{array}$ & $\begin{array}{l}\text { Spondylolisthesis/subluxation } \\
\text { Spinal canal stenosis } \\
\text { Vertebral autofusion } \\
\text { Cervical spine deformity } \\
\text { Kyphosis } \\
\text { Classic kyphosis } \\
\text { Sigmoid kyphosis } \\
\text { Reverse sigmoid kyphosis } \\
\text { Hyperlordosis } \\
\text { Scoliosis }\end{array}$ \\
\hline $\begin{array}{l}\text { Spinal cord } \\
\text { patholo- } \\
\text { gies that } \\
\text { can } \\
\text { appear in } \\
\text { DCM }\end{array}$ & $\begin{array}{l}\text { Intramedullary SI changes } \\
\text { T1WI: decreased SI } \\
\text { T2WI: increased SI } \\
\text { Type I: faint, diffuse, borders not clear } \\
\text { Type II: focal, sharp, clear borders } \\
\text { Type III: elements of Types I \& II } \\
\text { Cord compression } \\
\text { Cord flattening } \\
\text { Cord tethering } \\
\text { Decreased FA (DTI) } \\
\text { Increased apparent diffusion coefficient }\end{array}$ \\
\hline
\end{tabular}

» CONTINUED FROM PREVIOUS COLUMN

$\mathrm{SI}=$ signal intensity .

* Increased T2 intensity is seen on fast-spin echo images and marrow fat is dark on single-echo T2WI spin-echo sequences.

† Pathologies that include ossification and calcification of spinal ligaments are not easily discriminated with MRI and are better evaluated by using CT.

Therefore, it is imperative to always interpret MRI findings in the context of clinical symptoms and signs. In DCM, the following are $3 \mathrm{key}$ characteristics that indicate the severity of disc degeneration: 1) loss of T2WI hyperintensity of the nucleus pulposus and resulting loss of delineation between the nucleus pulposus and annulus fibrosus on T2WI, 2) narrowing of the IVD space, and 3) migration of disc material into the spinal canal. Both qualitative and quantitative methods for assessing these pathological features, with the purpose of classifying the degree of severity, have been described (Table 2).

On both T1WI and T2WI, the nucleus pulposus of the IVD is normally hyperintense compared with the surrounding annulus fibrosus. At the center of the nucleus, gelatinous matrix transforms into fibrous tissue as part of the natural aging process in most people by their 30 s, and this structure is referred to as the intranuclear cleft on MRI (Fig. 2C). ${ }^{1,95}$ With age, the rest of the nucleus pulposus also loses its signal intensity, which has been attributed to a progressive loss of water and proteoglycans and increased collagen..$^{8}$ Although this process can be considered part of normal physiology, it predisposes the discs to further degeneration, including loss of disc height, annulus tears, and herniations. ${ }^{117}$ This loss of intensity can be graded based on appearance as 1 of the following 2 types: 1) dark and/or speckled or 2) almost black. ${ }^{61,81}$

As the IVD degenerates, there is also frequently a loss of disc height, and in the most severe instances, the disc can collapse completely, which may be followed by autofusion of adjacent vertebrae (Fig. 2). Matsumoto et al. ${ }^{61}$ defined pathological narrowing as being 1 of the following 2 types: between $25 \%$ and $50 \%$ loss of height or more than $50 \%$ loss of height, when compared with the most adjacent normal-appearing disc. In addition, the simple midvertebral disc height can also be measured (Fig. 2A). It should be noted, however, that MRI sometimes fails to identify autofusion, so radiographs or CT images are useful adjuncts for assessing disc degeneration.

When the integrity of the annulus fibrosus is compromised, disc contents migrate toward the spinal canal. Matsumoto et al. ${ }^{61}$ defined disc protrusions as those in which disc material extends beyond the VB margin on T1WI and further differentiates their magnitude into 1 of 2 types, those that result in cord compression and those that do not. Alternatively, Nakashima et al. ${ }^{75}$ described a method for measuring the anterior-posterior length of disc migration into the canal by drawing a line between the posterior aspect of the adjacent vertebra at the region of interest (ROI) and measuring the extent of disc migration from that line (Fig. 2A).

On the basis of the aforementioned MRI findings, there have been attempts to create a comprehensive grading system for analyzing cervical disc degeneration. Matsumoto 
TABLE 2. MRI grading systems for assessment of cervical disc degeneration

\begin{tabular}{|c|c|}
\hline $\begin{array}{c}\text { Authors \& } \\
\text { Year }\end{array}$ & Classification \& Description \\
\hline $\begin{array}{l}\text { Matsumoto } \\
\text { et al., } \\
1998\end{array}$ & $\begin{array}{l}\text { Disc degeneration } \\
\text { 0: bright as or slightly less bright than CSF } \\
\text { 1: dark \&/or speckled } \\
\text { 2: almost black } \\
\text { Posterior disc protrusion } \\
\text { 0: disc material confined w/in the posterior margin of } \\
\text { the VB } \\
\text { 1: disc material protruding beyond the posterior } \\
\text { margin of the VB w/o cord compression } \\
\text { 2: beyond the posterior margin of adjacent VB \& } \\
\text { resulting cord compression } \\
\text { Narrowing of the disc space* } \\
\text { 0: no narrowing or }<25 \% \text { loss in height compared w/ } \\
\text { the most adjacent normal disc space } \\
\text { 1: } 25 \%-50 \% \text { loss of height } \\
\text { 2: }>50 \% \text { loss of height }\end{array}$ \\
\hline $\begin{array}{r}\text { Miyazaki et } \\
\text { al., } 2008\end{array}$ & $\begin{array}{l}\text { Grade I: hyperintense nucleus SI; nuclear structure } \\
\text { homogeneous, white; clear delineation btwn nucleus } \\
\text { \& annulus; normal disc height } \\
\text { Grade II: hyperintense nucleus SI; nuclear structure } \\
\text { inhomogeneous w/ horizontal band, white; clear delin- } \\
\text { eation btwn nucleus \& annulus; normal disc height } \\
\text { Grade III: intermediate nucleus SI; nuclear structure in- } \\
\text { homogeneous, gray to black; unclear delineation btwn } \\
\text { nucleus \& annulus; normal or decreased disc height } \\
\text { Grade IV: hypointense nucleus SI; nuclear structure } \\
\text { inhomogeneous, gray to black; delineation btwn } \\
\text { nucleus \& annulus is lost; normal or decreased disc } \\
\text { height } \\
\text { Grade V: hypointense nucleus SI; nuclear structure inho- } \\
\text { mogeneous, gray to black; delineation btwn nucleus \& } \\
\text { annulus is lost; disc height is collapsed }\end{array}$ \\
\hline $\begin{array}{c}\text { Nakashima } \\
\text { et al., } \\
2015 \dagger\end{array}$ & $\begin{array}{l}\text { Based on a modified Pfirrmann classification } \\
\text { Grade I: inhomogeneous white structure w/ possible } \\
\text { horizontal bands } \\
\text { Grade II: clear distinction btwn annulus \& nucleus } \\
\text { Grade III: unclear annulus \& nucleus degeneration but } \\
\text { no disc collapse } \\
\text { Grade IV: collapsed disc space }\end{array}$ \\
\hline
\end{tabular}

* Okada et al. ${ }^{81}$ modified this version to state that the most adjacent normal disc superior to the disc of interest should be used.

$\dagger$ The classification presented was modified from the original because of a correction submitted by the authors.

et al. ${ }^{61}$ described a score that accounted for disc T2WI signal intensity, anterior and posterior protrusion, narrowing of disc space, and foraminal stenosis. Another grading system for cervical disc degeneration and its reliability were described by Miyazaki et al., ${ }^{65}$ who segregated the severity of disc degeneration into 5 grades. Finally, a more recent grading system based on a modified Pfirrmann score $^{89}$ was described by Nakashima et al. ${ }^{75}$ These classifications are described in Table 2. Other classification systems for disc degeneration have been reported, but they are outdated, were focused on lumbar discs, or were based on radiographs..$^{45,49,50,97}$

\section{Vertebral Body Degeneration, Remodeling, and Osteophytosis (spondylosis)}

Degenerative changes that affect the VBs likely occur as a result of excessive static and dynamic forces, with flattening of the VBs, broadening in the anteroposterior direction (spondylosis), and formation of osteophytes at the site of severely degenerated discs. Although VB changes can occur anywhere in the cervical region, there is a strong predilection for the C5-6 region. ${ }^{43,76}$ There are also notable changes in signal intensity within the VBs and their endplates that can appear on MRI, and perhaps the most well-known descriptions of these changes were reported by Modic et al. ${ }^{67}$ The authors described the following 3 notable types of changes that can occur on MRI: Type I, inflammatory changes (bone marrow edema) (Fig. 3A and B); Type II, local fatty replacement of bone marrow (Fig. 3C and D); and Type III, reactive osteosclerosis. ${ }^{67} \mathrm{It}$ has been suggested that Type II changes occur most frequently, particularly in the C5-6 and C6-7 regions. ${ }^{57}$ The clinical significance of these changes in terms of DCM is unclear, but there is evidence supporting an association of Type I changes with both cervical and lumbar back pain. ${ }^{88,134}$ It has also been suggested that Type I changes might be an indicator of early degenerative changes that transition over time to Type II changes. ${ }^{57,134}$

Commonly seen in the lumbar region, the occurrence of Schmorl's nodes in the cervical spine has been reported rarely. ${ }^{8,54}$ The etiology has been described as being a consequence of disc herniation through the endplate and into the $\mathrm{VBs}$, resulting in a visible pit or notch ${ }^{62}$ (Fig. 4A and B). Other than the notch, the appearance on MRI can be variable. In some cases, hyperintense disc material can be appreciated in the herniation, but the notch can also be hypointense on T2WI. A sclerotic rim surrounding the notch, described as hypointense on both T1WI and T2WI, may also be appreciated..$^{32,127}$ The relationship between Schmorl's nodes and DCM is unclear.

In terms of osteophytes or spondylotic changes, there is no agreed-on classification or guideline based on MRI, and the only study to have differentiated spondylosis severity based on radiographs was described by Kellgren and Lawrence ${ }^{45}$ more than 50 years ago. However, osteophytes can frequently be appreciated (Fig. 4C), although they may be more clearly visible on radiographs or CT images.

\section{Ligamentous Pathology}

The ligaments within the spinal canal (PLL and LF) occupy relatively small amounts of space in patients without pathology. However, hypertrophy, ossification, and calcification can occur over time, reducing canal size and potentially compressing the spinal cord. ${ }^{77}$

Anterior compression of the cord can occur through hypertrophy or ossification of the PLL. Standard T2WI and T1WI do not provide a clear distinction between the PLL and disc material, because both of these structures appear hypointense on both sequences. ${ }^{117}$ However, efface- 

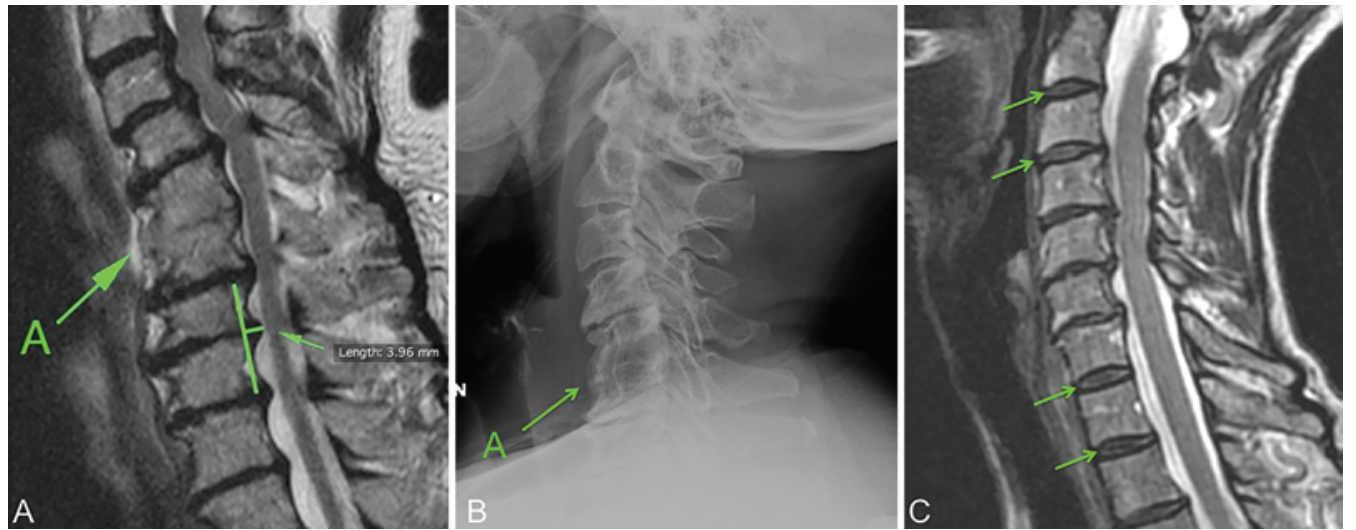

FIG. 2. $A$ and $B$ : A patient with DCM with autofusion of $C-5$ and $C-6$ and loss of the IVD at this level. A: Midsagittal T2WI showing autofusion $(A)$ and the quantitative method for measuring the horizontal posterior disc protrusion, as described by Nakashima et al. ${ }^{75}$ B: Lateral radiograph of the same patient showing autofusion (A) between C-5 and C-6. C: Sagittal T2-weighted MR image in a patient with DCM. With age, the center of the nucleus pulposus changes into fibrous tissue, which is part of the natural physiological aging process. This change is visible on MRI and has been referred to as the intranuclear cleft (arrows). Also note the degenerated Grade I retrolisthesis of C4-5 associated with cord compression and T2 signal hyperintensity within the spinal cord.

ment of the anterior CSF and spinal cord compression that is contiguous across multiple levels, or in the absence of spondylotic changes, are highly suggestive of ligament pathology. Ossification is not clearly evident on MRI, with
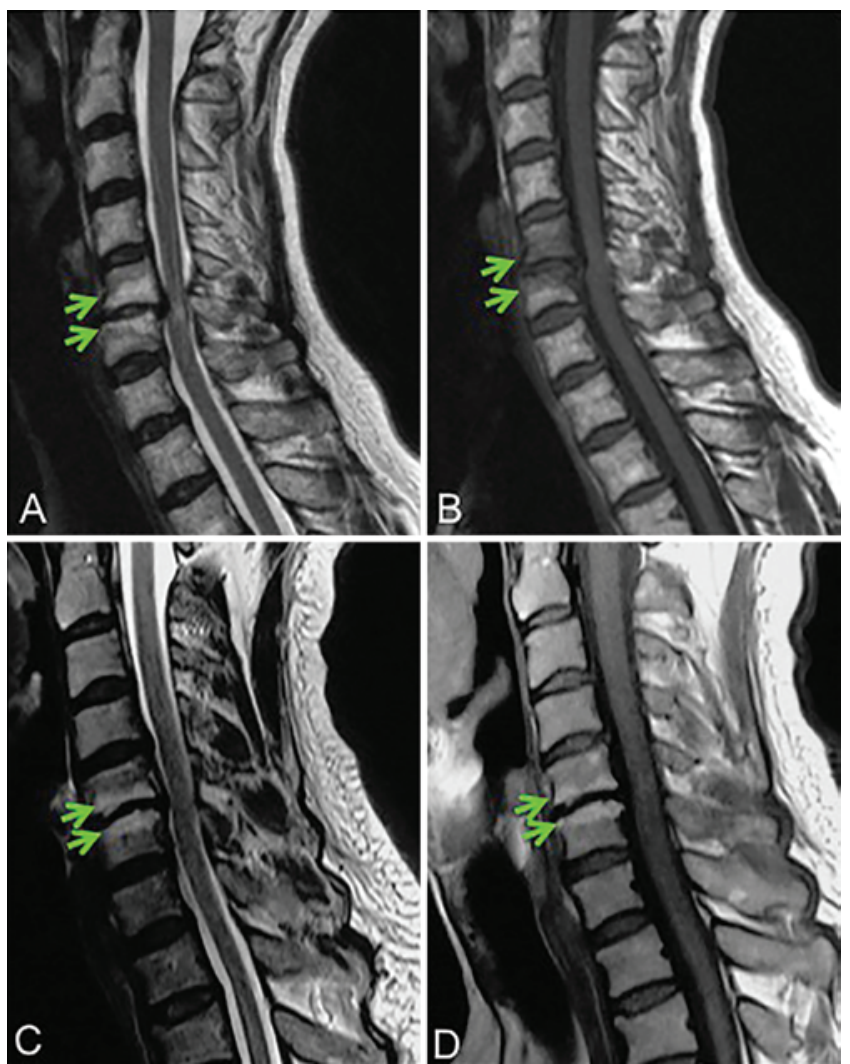

FIG. 3. Two patients with DCM and Modic changes on T2WI and T1WI. Modic changes are typically well delineated adjacent to vertebral endplates (arrows). A: Type I Modic changes appear hyperintense on T2WI and are present at the C5-6 region. B: These changes appear hypointense on T1WI. C and D: Type II Modic changes are indicated by the presence of hyperintense changes on both MRI sequences and are present in the $\mathrm{C} 5-6$ region in this patient. a sensitivity of only $49 \%,{ }^{128}$ so CT remains the preferred imaging modality for its assessment. Some reports have suggested that hypertrophy of the PLL (HPLL) shows as an isointense or a slightly hyperintense mass compared with the paravertebral muscles on T1WI and that it can be distinguished from ossification of the PLL (OPLL) and osteophytes, which appear hypointense ${ }^{37,66}$ (Fig. 4B). Several classification systems for OPLL have been proposed, and the most common one of these segregates OPLL into the following distribution patterns: 1) continuous, 2) segmental, 3) mixed, or 4) nodular, circumscribed, or bridged. ${ }^{83,105}$

Posterior compression of the spinal cord can occur through buckling and hypertrophy of the LF, ossification, and, rarely, calcification..$^{31,64,77}$ Because the LF is thinnest at the midline, examination results might be most significant on parasagittal slices. ${ }^{108}$ As with the PLL, the LF appears hypointense on both T1WI and T2WI sequences. ${ }^{117}$ It is challenging to discern between hypertrophy and ossification or calcification of the LF on MRI; therefore, CT can be helpful, particularly if anterior surgical decompression is being contemplated and the LF contributes substantially to cord compression.

\section{Sagittal Alignment}

It is becoming increasingly recognized that sagittal alignment might be a contributor to disease severity in patients with DCM and is certainly an important factor in the selection of an anterior or posterior surgical approach. ${ }^{4,68}$ Therefore, assessment of the cervical spine should include evaluation for scoliosis, hyperlordosis, and kyphosis. Sagittal balance and alignment can be assessed optimally by using standing radiographs of the whole spine, but some measurements, made by using cervical MRI, have been reported, and they might prove useful in the absence of upright films.

For assessing cervical kyphosis, Ruangchainikom et al..$^{92}$ used a previously described but modified method for radiographs ${ }^{80}$ which classified cervical kyphosis as 1 of 3 forms: C type (global), S type (sigmoid), and R type (re- 


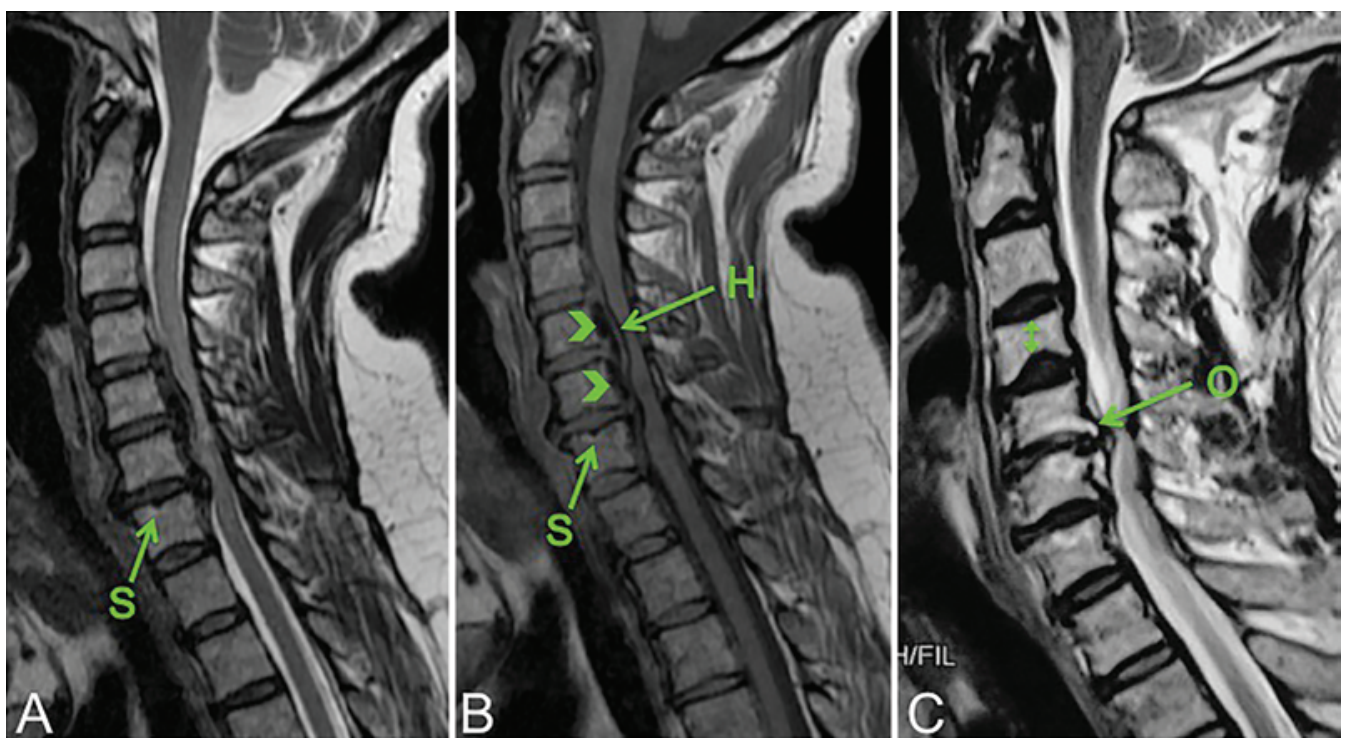

FIG. 4. MRI of patients with DCM. T2WI (A) and T1WI (B) studies showing a Schmorl's node at the superior endplate of C-7 (S), OPLL extending from C-4 to C-7 (arrowheads), and hypertrophy of the PLL (H). C: T2WI study showing widespread spondylotic changes of the cervical spine with decreased vertebral height noted in C-4 (double arrow) and a large posterior osteophyte (O).

verse sigmoid). In addition to the assessment of kyphosis, the radiographic method also included criteria for evaluating hyperlordosis, which presumably would also be feasible for adoption with MRI. It has been shown also that MRI has utility similar to that of radiographs for the assessment of thoracolumbar kyphosis and scoliosis using Cobb angle measurement. ${ }^{15,96,106,126}$ However, the reliability and validity of MRI-based Cobb angle measurements for evaluating the cervical region have yet to be established.

Another measurement technique that can be used to assess cervical curvature was described by Batzdorf and Batzdorff ${ }^{13}$ for radiographs and later used on MRI by Chen et al ${ }^{19}$ For this measurement, a line is drawn from the posteroinferior aspect of the C-2 VB to the posteroinferior aspect of the C-7 VB, and no portion of the C3-6 VB should cross the drawn line. ${ }^{13,19}$ Ames et al. ${ }^{4}$ also described several additional measures of cervical sagittal alignment based on radiographs, including the chin brow vertical level, the T-1 slope, the sagittal vertical axis, the Harrison posterior tangent method, and Jackson physiological stress lines, ${ }^{4}$ but the validity of these measurements using MRI has yet to be reported in the literature. Overall, the supine positioning of patients for conventional MRI limits its utility in assessing alignment, but at least it can provide a superficial assessment of alignment for scenarios in which upright films are unavailable.

With the emergence of flexion/extension and upright MRI technology, new methods of assessing cervical alignment might appear in the near future; however, given the low cost, easy access, and proven utility of radiographs, the role of more sophisticated MRI-based techniques in assessing alignment and stability is unclear.

\section{Spondylolisthesis}

Spondylolisthesis of the cervical spine is relatively common $^{111}$ and occurs as a result of instability arising from facet and IVD joint degeneration and from hypermobility syndromes such as Ehlers-Danlos syndrome. ${ }^{77}$ Given the static nature of conventional MRI, movement-dependent spondylolisthesis can be missed; therefore, when it is suspected, flexion and extension radiographs should be evaluated. The earliest and most commonly used classification of spondylolisthesis based on plain radiographs was described by Meyerding in $1932 .{ }^{63}$ This classification grades the degree of vertebral displacement by quartiles, and recently, an additional grade for complete displacement was also recognized (Table 3). Another method, described more recently by Kawasaki et al., ${ }^{44}$ measures the distance between the posterior margin of the normal and abnormal VBs, which is achieved by drawing lines perpendicular to the superior endplate of the vertebrae immediately below the listhesis. It is generally recognized that patients with greater than 3-3.5 mm of horizontal translation have severe listhesis. ${ }^{44,111}$ However, the reliability and validity of these methods using MRI remain to be determined.

Recent research using dynamic/kinematic MR images, the equivalent of lateral extension and flexion radiographs, has shown efficacy in evaluating movement-dependent cord compression..$^{92,111}$ Indeed, Hayashi et al. ${ }^{34}$ recently reported that missed dynamic stenosis was discovered in $8.3 \%$ in neck extension and $1.6 \%$ in neck flexion using kinematic MRI in a cohort of patients with neck pain and clinical signs of radiculopathy or myelopathy. Therefore,

TABLE 3. Summary of grades in the Meyerding classification*

\begin{tabular}{cc}
\hline Grade & Displacement $(\%)$ \\
\hline I & $<25$ \\
II & $\geq 25,<50$ \\
\hline III & $\geq 50,<75$ \\
\hline IV & $\geq 75,<100$ \\
\hline V & $\geq 100$ \\
\hline
\end{tabular}

* An increase in grade indicates an increase in vertebral displacement. 
consideration of movement-dependent compression should always be considered, particularly in patients without clear cord compression.

\section{Spinal Canal Stenosis}

The relationship between canal size and spinal cord compression is clear, and reduced canal size through either acquired degenerative disease or congenital stenosis renders a person susceptible to myelopathy through static or dynamic injury. ${ }^{77}$ Methods for assessing canal size, such as the TorgPavlov body-to-canal ratio, have been used frequently in the literature. ${ }^{87}$ The definition of what constitutes canal stenosis has been estimated as a spinal canal diameter of $<13$ $\mathrm{mm}^{9}$ and a Torg-Pavlov ratio of $<0.82 ; ;^{87}$ it is unfortunate, however, that these estimates derive from radiographic and cadaveric studies and are not well correlated with MRI parameters. ${ }^{43,100}$ Unlike MRI, radiographic methods do not take into consideration soft-tissue structures in the canal that might contribute to compression of the spinal cord, and they are not optimal for assessing canal stenosis that results from degenerative causes of myelopathy. With the possibility of demarcating the thecal sac from surrounding hypointense ligamentous tissue, particularly using T2WI, MRI also offers an opportunity to assess a reduction in the canal space that might be related to soft-tissue structures. To the best of our knowledge, there currently are no clear quantitative criteria for defining congenital or acquired canal stenosis by using MRI. Recently, however, Kato et al. ${ }^{43}$ proposed an MRI-based definition based on the normal morphology of spine parameters. The authors suggested measuring an "occupation rate" of the spinal cord within the dural tube by dividing the sagittal diameter of the cord by the sagittal diameter of the neural tube, as viewed on sagittal T2WI. The authors suggested that this measurement provides a more appropriate assessment of whether a patient has congenital stenosis than methods that take into consideration only canal size, because such methods do not take into consideration variability in spinal cord size or soft-tissue structure within the spinal canal. Based on their finding that the mean occupation rate at the C-5 vertebral level was $58.3 \% \pm 7.0 \%$ and that the upper limit of $72.3 \%$ was 2 standard deviations away, the authors proposed that an occupation rate of $75 \%$ or greater indicates congenital stenosis. $^{43}$

In the setting of spinal cord compression, assessment of canal stenosis on MRI has been conducted using several methods. Simple measurements of the anterior-posterior diameter at the ROI have been used in past studies, ${ }^{99,131}$ but recognizing that canal size varies among individuals supports the idea that any measurement at the region of stenosis should be related to normal reference values. Maximum canal compromise (MCC) assesses canal size at the ROI by comparing it to the average canal size at normal sites above and below it. ${ }^{26}$ This method was devised originally for traumatic spinal injury and assesses canal size by using anterior and posterior osseous borders on T1WI sagittal views. Recently, this method was modified for use with T2WI; the delineation of the borders of the canal was defined by the limits of visible CSF both anterior and posterior to the spinal cord 5,78 (Fig. 5A).

\section{Spinal Cord Compression}

Spinal cord compression can be described based on appearance ${ }^{40,71,101,111,113}$ or by measuring the number of compression sites, ${ }^{131}$ a ratio between the anteroposterior diameter at the compressed site and that of a noncompressed

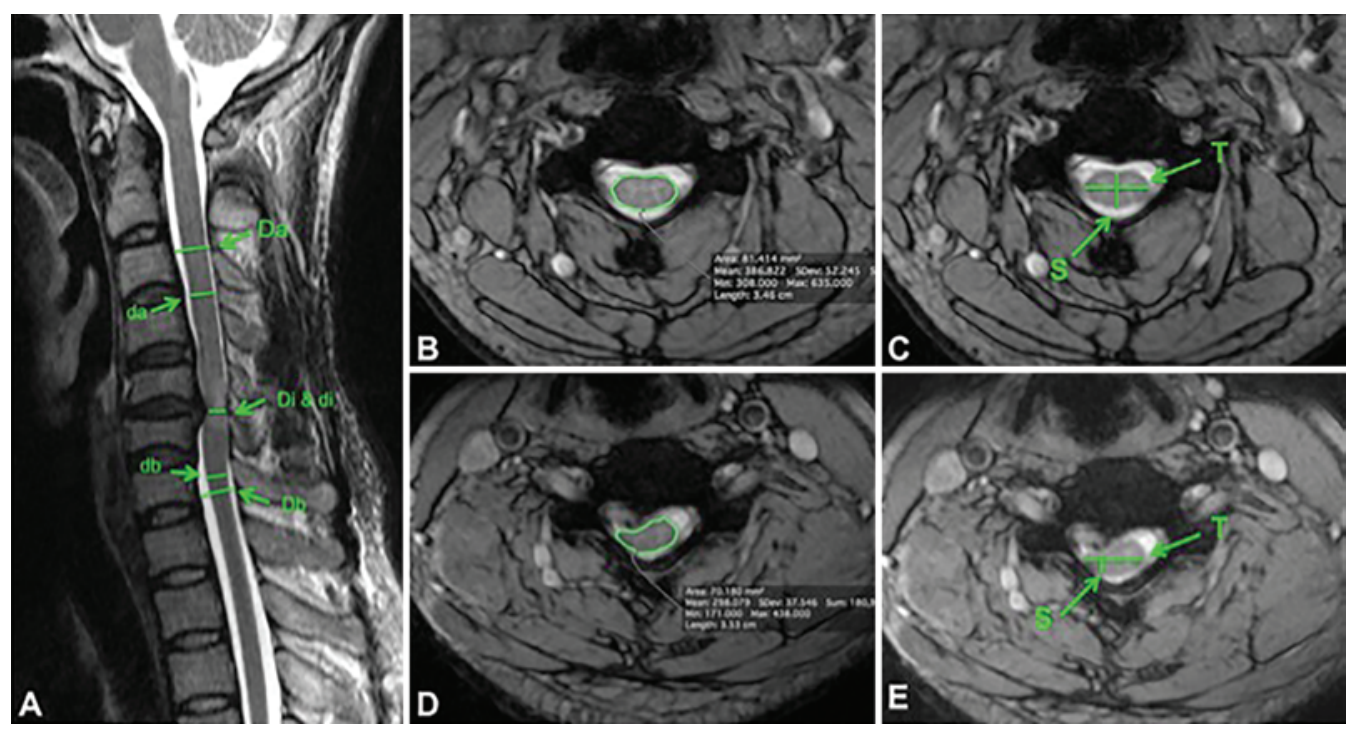

FIG. 5. T2WI MR images of patients with DCM. A: Midsagittal image showing the measurements required for determining the MSCC and MCC. As is often the case, the sagittal diameters of the canal (Di) and cord (di) in this patient are the same at the region of greatest compression. The normal cord diameters above (da) and below ( $d b$ ) and the normal canal diameters above (Da) and below $(D b)$ the ROI are used as reference values for calculating the MSCC and MCC, respectively. B and C: Axial views showing the measurement of CSA and CR at a noncompressed level, respectively, in a patient with DCM. D and E: Axial views showing the measurement of CSA and CR at the site of greatest compression, respectively, in a patient with DCM. The CR method is frequently calculated in T1WI. S = sagittal; $T$ = transverse. 
site, ${ }^{26,84}$ a ratio between the anteroposterior diameter and the transverse diameter (compression ratio [CR]), ${ }^{28,82}$ or the CSA at the region of compression ${ }^{70,82}$ (Table 4, Fig. 5). Regardless of the method used, the objective of these measurements is to determine the severity of spinal cord compression. Indeed, spinal cord compression is a sensitive marker of myelopathy, ${ }^{33}$ but it can also present in approximately $5 \%$ of asymptomatic patients, ${ }^{43}$ which limits its specificity. From the many methods mentioned, the CR described by Fujiwara et al. ${ }^{28}$ initially for CT myelography and later adopted by multiple authors for assessments via MRI with T1WI,${ }^{19,82,102}$ and the method of maximum spinal cord compression (MSCC) described by Fehlings et al. ${ }^{26}$ have been used regularly and are reported in the literature. ${ }^{5,6,78}$ The concept behind CR is based on the findings that cord compression typically results in a reduction of anteroposterior diameter and an increase in the lateral diameter. Although both MSCC and CR have shown utility, they do have notable limitations. The CR, for example, would not be a valid measurement for patients in whom compression occurs simultaneously in the sagittal and lateral directions (i.e., circumferentially).$^{41}$ In addition, the cord is not a rectangular shape, and thus, the CR may overestimate sagittal compression when the compression is measured laterally. In terms of MSCC, variation in cord size within the cervical spine should be considered, and also, given that compression is assessed at the midsagittal plane, lateral cord compression is poorly quantified. Therefore, it is clear that both sagittaland axial-based examinations of the cord are necessary to ensure thorough analysis.

These measures of spinal cord compression are useful not only for evaluating the severity of patients with DCM;

TABLE 4. Previously reported methods for assessing spinal cord compression

\begin{tabular}{|c|c|c|}
\hline Type & Method \& Description & Reliability \\
\hline \multirow[t]{3}{*}{ Sagittal qualitative* } & $\begin{array}{l}\text { Degree of spinal cord compression }{ }^{70,113} \\
\text { 0: no thecal sac compression } \\
\text { 1: minimal degree of subarachnoid space compression } \\
\text { 2: mild spinal cord compression } \\
\text { 3: severe compression or cord atrophy }\end{array}$ & Requires further investigation \\
\hline & $\begin{array}{l}\text { Degree of spinal canal stenosis }{ }^{71} \text { (a slightly modified version has also been } \\
\text { described }{ }^{92} \text { ) } \\
\text { 0: normal width of the spinal canal, no signs of anterior or posterior sub- } \\
\text { arachnoid space narrowing } \\
\text { 1: partial obliteration of anterior or posterior subarachnoid space or both } \\
\text { 2: complete obliteration of anterior or posterior subarachnoid space or both } \\
\text { 3: anterior or posterior cord impingement or both (pincer effect) }\end{array}$ & $\begin{array}{l}\text { Intraobserver \& interobserver reliabilities were } \\
\quad 0.823 \& 0.756 \text {, respectively }{ }^{71}\end{array}$ \\
\hline & $\begin{array}{l}\text { Grade of spinal canal stenosis }{ }^{40} \\
\text { 0: normal } \\
\text { 1: obliteration of }>50 \% \text { of subarachnoid space w/o any sign of cord defor- } \\
\text { mity } \\
\text { 2: central canal stenosis w/ spinal cord deformity; cord is deformed but no } \\
\text { signal change is noted in spinal cord } \\
\text { 3: increased SI of spinal cord near compressed level on T2WI }\end{array}$ & $\begin{array}{l}\text { The ICC, percent agreement, \& weighted kappa } \\
\text { for all readers were } 0.735,63 \%, \& 0.62 \text {, } \\
\text { respectively; the ICC, percent agreement, \& } \\
\text { weighted kappa for experienced readers were } \\
0.753,67 \%, \& 0.65 \text {, respectively }{ }^{40}\end{array}$ \\
\hline \multirow[t]{4}{*}{ Sagittal quantitative } & $\begin{array}{l}\text { MSCC, } 5,6,26,78 \text { ratio of the midsagittal diameter of the spinal cord at the } \\
\text { compression site divided by the average diameter of the spinal cord at the } \\
\text { closest noncompressed regions above \& below }\end{array}$ & $\begin{array}{l}\text { Intraobserver \& interobserver ICCs were previ- } \\
\text { ously reported as } 0.88 \pm 0.1 \& 0.75 \pm 0.04 \text { for } \\
\text { the T1WI MCC, respectively }{ }^{41}\end{array}$ \\
\hline & $\begin{array}{l}\text { Sagittally based CR; }{ }^{84} \text { spinal cord compression was measured by comparing } \\
\text { the diameter at the level of greatest compression to the diameter at the C-1 } \\
\text { level using T2-weighted MRI }\end{array}$ & Requires further investigation \\
\hline & $\begin{array}{l}\text { Absolute value of sagittal cord diameter at most compressed site was mea- } \\
\text { sured }^{99}\end{array}$ & Requires further investigation \\
\hline & The number of segments compressing the cord $99,110,115,121,131$ & Requires further investigation \\
\hline Axial qualitative & $\begin{array}{l}\text { Type of spinal cord compression: } 101 \\
\text { differentiated cord compression as partial or circumferential at the site of } \\
\text { greatest compression }\end{array}$ & $\begin{array}{l}\text { Intraobserver \& interobserver reliability indicated } \\
\text { concordance rates of } 98.2 \% \& 96.4 \% \text { \& kappa } \\
\text { coefficients of } 0.96 \& 0.93 \text {, respectively }{ }^{101}\end{array}$ \\
\hline \multirow[t]{2}{*}{ Axial quantitative } & $\begin{array}{l}\text { Compression ratio: } 19,82,102,115 \\
\text { the ratio of the sagittal diameter divided by the transverse diameter of the } \\
\text { spinal cord observed on axial T1WI }\end{array}$ & $\begin{array}{l}\text { Intraobserver \& interobserver ICCs were previ- } \\
\text { ously reported as } 0.82 \pm 0.13 \& 0.80 \pm 0.05 \\
\text { for the T2WI CR, respectively }{ }^{41}\end{array}$ \\
\hline & $\begin{array}{l}\text { Absolute value of transverse area of the spinal cord measurement at site of } \\
\text { compression } \\
\text { co,82,115,121 }\end{array}$ & $\begin{array}{l}\text { Intraobserver \& interobserver ICCs were previ- } \\
\text { ously reported as } 0.92 \pm 0.07 \& 0.86 \pm 0.03 \\
\text { for the T2WI axial area, respectively }{ }^{41}\end{array}$ \\
\hline
\end{tabular}

ICC = intraclass coefficient.

${ }^{*}$ Methods that were described as measures that assess canal stenosis but include spinal cord compression. 
they also can be used to evaluate cord expansion after surgical decompression. Indeed, there is evidence to suggest that expansion of the cord is related to good surgical outcome $^{60}$ and that lack of expansion 6 months after surgery indicates poor surgical outcome at 1 year. ${ }^{5}$

\section{Myelopathy_Intramedullary Cord Signal Change Characteristics}

Intramedullary signal changes occur within the spinal cord on T1WI and T2WI as a result of changes in tissue relaxation, which are directly related to water content: as the severity of the cord injury increases, water content increases. Greater water content increases T1 and T2 relaxation (which makes tissue appear hypointense on T1WI and hyperintense on T2WI because of differences in how these parameters are detected in MRI), but it affects T2 more so and is later followed by increased T1. This is the reason why bright $\mathrm{T} 2$ lesions can appear with normal T1 images but $\mathrm{T} 1$ hypointense lesions will not appear without T2 hyperintensities unless there is hemorrhage. When T1 and T2 match the appearance of the CSF, the presence of a fluid-filled cavity is highly suggested.

In the setting of DCM, intramedullary signal changes of the spinal cord are observed frequently and indicate a host of physiological processes, including edema and structural changes. Patients with DCM most commonly have hyperintensity on T2WI and, less commonly, hypointensity on T1WI (Fig. 6). Indeed, these changes, particularly in terms of T2WI, are useful diagnostic markers of DCM. The prevalence of hyperintense signal on T2WI among patients with clinically confirmed DCM has been reported within the range of $58 \%-85 \%$. $^{19,33,60,74,78,94,102,103,110,115,118,121}$ In contrast, it was reported recently that incidental T2WI hyperintensity occurred in $2.3 \%$ of asymptomatic subjects in a Japanese population cohort. ${ }^{43}$
However, not all T2WI signal changes are the same, and it has become increasingly recognized that these changes appear in 2 broad forms depending on the degree of intensity deviation and the visual quality of the signal change. ${ }^{114,120}$ Vedantam and Rajshekhar ${ }^{120}$ recently summarized a number of qualitative categorization methods derived from other authors, and although there were subtle variations in the descriptions, T2WI hyperintensity was generally defined as either strongly hyperintense and well circumscribed (Type II) or less hyperintense and diffuse (without a clear margin) (Type I). It is thought that these changes represent different states of pathology and have different recovery potentials ${ }^{114,120}$ (Table 5). It is important to recognize, however, that some patients can present with a combination of Type I and II hyperintensity (Fig. 6C). Quantitative methods for determining signal intensity deviation have been described also. ${ }^{5,78,82,122,133,135}$ These methods are conducted by calculating the intensity within the ROI and are compared to a signal references site, which, depending on the method, can be within normal-appearing cord or CSF. Lower signal intensity deviation is seen typically with Type I, and greater signal intensity deviation is seen typically with Type II T2WI hyperintensities. In addition, Type II T2WI hyperintensities are accompanied more frequently by hypointensity on T1WI, which is not surprising, given that these changes seem to represent the same histopathology. However, no validated threshold currently exists for differentiation of pathologies based on T2WI intensity deviations.

A notable limitation to these T2WI assessment techniques occurs when there are multiple discontinuous regions of T2WI signal hyperintensity on sagittal imaging, although that occurs in only a minority of patients. Arvin et al. ${ }^{5}$ called this finding segmentation (Fig. 6D) and showed that patients with preoperative T2WI segmentation had greater disturbances in gait function. ${ }^{6}$
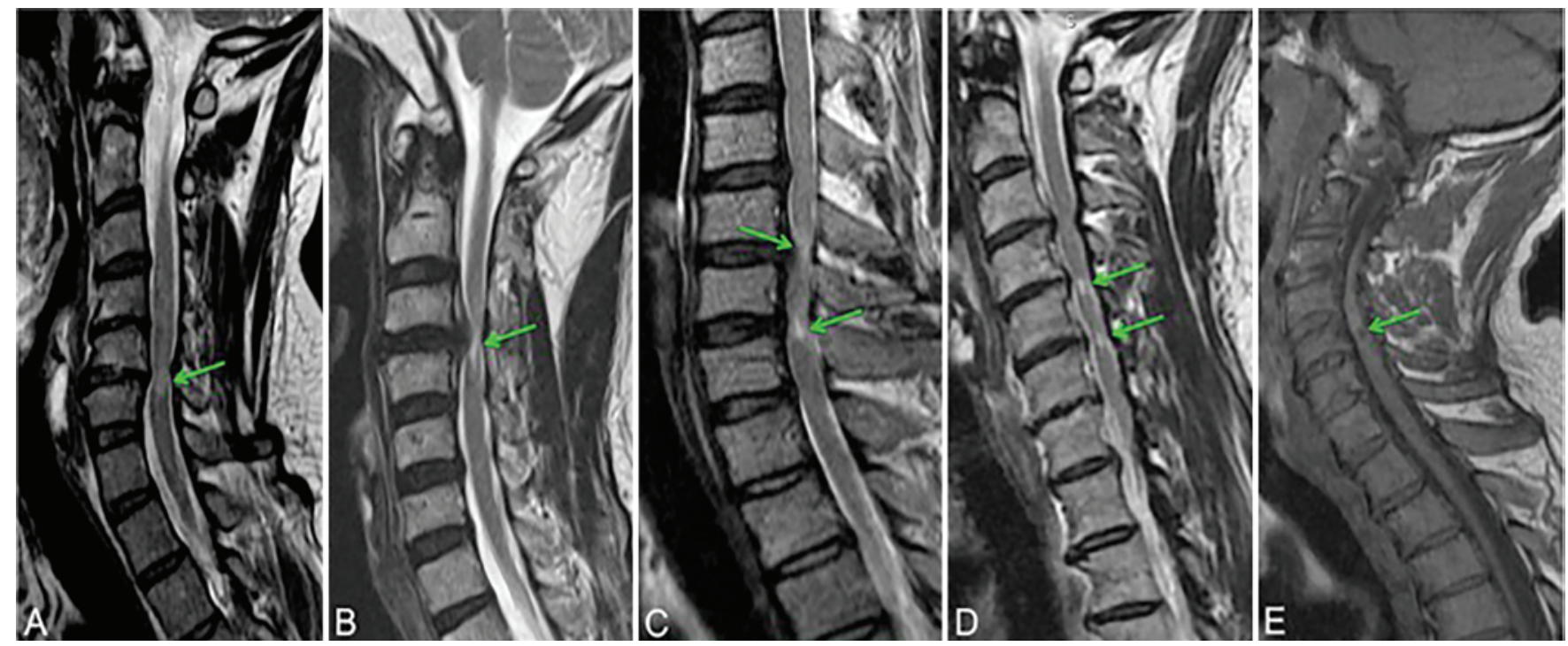

FIG. 6. Types of signal changes that can appear in patients with DCM. A-D: Sagittal T2WI. A: Type I, diffuse and faint hyperintensity. B: Type II, focal and sharp hyperintensity. C: Type III, both Type I (higher arrow) and Type II (lower arrow) hyperintensity characteristics are present. D: Two discontinuous focal hyperintensities are present. E: Sagittal MRI with T1WI showing a focal hypointensity. 
TABLE 5. Correlation between MRI characteristics and histopathological changes and current thoughts related to structure recovery potential after decompression surgery

\begin{tabular}{cccc}
\hline $\begin{array}{c}\text { Imaging } \\
\text { Type }\end{array}$ & MRI Characteristics & Likely Pathobiological Correlation & Structural Change \\
\hline $\mathrm{T}_{2} \mathrm{WI}^{*}$ & $\begin{array}{c}\text { Weak signal hyperintensity (brighter than spinal cord but darker } \\
\text { than CSF SI); appearing bright, fuzzy, diffuse, w/o clear } \\
\text { border/delineation }\end{array}$ & $\begin{array}{c}\text { Edema; Wallerian degeneration; demyelination; } \\
\text { ischemia; gliosis }\end{array}$ & $\begin{array}{c}\text { Considered } \\
\text { reversible }\end{array}$ \\
\cline { 2 - 5 } & $\begin{array}{c}\text { Strong signal hyperintensity (approaching isointensity w/ CSF); } \\
\text { appearing bright, focal, sharp, clear border/delineation }\end{array}$ & $\begin{array}{c}\text { Potential cavitation; neural tissue loss; myelomala- } \\
\text { cia; necrosis; spongiform changes in gray matter }\end{array}$ & $\begin{array}{c}\text { Considered largely } \\
\text { irreversible }\end{array}$ \\
\hline T1WI† & $\begin{array}{c}\text { Remarkable presence of signal hypointensity (approaching } \\
\text { isointensity w/ CSF); appearing dark, focal, faint }\end{array}$ & $\begin{array}{c}\text { Cavitation; neural tissue loss; myelomalacia; necro- } \\
\text { sis; spongiform changes in gray matter }\end{array}$ & $\begin{array}{c}\text { Considered largely } \\
\text { irreversible }\end{array}$ \\
\hline
\end{tabular}

* T2WI signal hyperintensity changes are nonspecific and can represent either reversible or irreversible structural alterations. It should be noted that patients might have a combination of both weak and strong T2WI signal hyperintensity elements.

† T1WI signal hypointensity changes more specifically represent frank neural tissue loss. ${ }^{2,19,41,114}$

Most studies that described the significance of T2WI signal changes focused on sagittal imaging, but a classification system based on axial image characteristics was also described recently. ${ }^{132}$ The authors defined the following 4 types of changes: Type 0 , normal pattern; Type 1 , diffuse pattern; Type 2, fuzzy focal pattern; and Type 3, discrete focal pattern. ${ }^{132}$ However, this classification remains to be validated.

In comparison with T2WI hyperintensity, T1WI hypointensity is much more difficult to observe reliably, and its prevalence is much lower. ${ }^{78,132}$ Based on recent evidence, it seems that although T1WI hypointensity is not a sensitive diagnostic marker, it is specific and is a marker for greater baseline neurological deficits and worse surgical outcome..$^{3,6,69,78}$ No grading system specifically for T1WI hypointensity has been devised, but a characteristic "snake-eye" appearance on the axial view has been described. ${ }^{2}$

\section{Myelopathy-Size of Intramedullary Spinal Cord Signal Intensity Changes}

Mounting evidence suggests that a larger area of signal intensity changes on T2WI, and in particular sagittal extent, is related to the severity of impairment in patients with DCM. 5,78,119,120

Geometrical measurement of T2WI hyperintensity can include measuring the area on sagittal (or axial) images, the rostrocaudal sagittal extent, or the volume of signal change (across slices). Most research to date has focused on the number of vertebral levels that the T2WI hyperintensity spans ${ }^{103}$ or differentiating between focal or multisegmental changes. ${ }^{7,18,60,121}$ The length of the sagittal extent, ${ }^{5,78,119}$ which offers the advantage of obtaining an objective value, was also described more recently.

The planar area of T2WI hyperintensity has been described infrequently, $,, 6,78$ and the utility of this measurement is unclear. Assessing the planar area is challenging, because the border of the T2WI signal intensity can be obscure and can change when the contrast of the imaging is altered if a manual method is used, which ultimately might explain its infrequent reporting. Similarly, the number of sagittal slices with a T2WI hyperintensity has also been reported infrequently, 5,6 and although interesting, such a metric is a poor measure of volume, because it depends on slice thickness and gap size. Volumetric analysis, based on planar measurements over several slices, is also relatively straightforward to perform, but to our knowledge, it has not been reported in the literature.

\section{DCM and Contrast-Enhanced MRI}

Contrast enhancement with Gd can reveal areas of blood-spinal cord barrier disruption. It is not typical for patients with DCM to be evaluated using contrast-enhanced MRI, but it might serve to exclude other causes of myelopathy in cases of diagnostic uncertainty. The differential diagnosis includes vascular, inflammatory, infective, neoplastic, and demyelinating diseases..$^{16}$ It was suggested recently that a pancake-like Gd enhancement of the spinal cord on sagittal images immediately below the area of compression and circumferential enhancement on axial images in patients with intramedullary lesions found with T2WI are strongly indicative of DCM. ${ }^{27}$ Another study found a $7.3 \%$ prevalence of intramedullary Gd enhancement in 683 cases of cervical myelopathy and suggested that enhancement was seen most commonly approximating the site of compression. ${ }^{85}$ Furthermore, this study also found that there was a statistically significant inferior recovery potential in patients whose imaging showed enhancement. The presence of enhancement in only some cases of DCM diminishes the diagnostic utility of this technique, and it is unlikely to provide additional information beyond that obtained from T1WI and T2WI for the vast majority of patients. Furthermore, Gd testing has a number of disadvantages; it is invasive, it can cause a hypersensitivity reaction, it requires an assessment of kidney function, and it is very expensive. Therefore, further research is required to demonstrate its clear diagnostic utility.

\section{Future of Spinal Cord Imaging}

Conventional MRI is a powerful tool for providing detailed views of the anatomy, but it is inherently limited in its ability to characterize spinal cord tissue injury, because T1WI and T2WI signal change are nonspecific and do not reflect specific pathophysiological processes that occur at the cellular level, including edema, inflammation, gliosis, demyelination, axonal loss, and apoptosis. Advanced imaging techniques have the potential to quantify changes 
in spinal cord microstructure and function that ultimately might offer better diagnostic tools, correlation with impairment, and prediction of long-term outcomes.

\section{Advanced MRI Techniques}

An international meeting of spinal cord imaging experts, invited by the International Spinal Research Trust and the Wings for Life Spinal Cord Research Foundation, outlined 5 techniques that can elucidate details of the microstructure and functional organization within the spinal cord. ${ }^{107}$ This group identified the following microstructural assessment techniques: diffusion tensor imaging (DTI), magnetization transfer (MT), myelin water fraction (MWF), and MR spectroscopy (MRS). DTI measures the directional diffusivity of water within each voxel, and the quantitative metrics that it generates are representative of axonal integrity. The MT technique involves selective radiofrequency excitation of protons in water molecules "bound" to macromolecules, which provides a measure of myelin quantity and is expressed in a ratio (MTR) between scans with and without the pre-pulse or between the spinal cord and CSF (MTCSF). The MTR is more myelin specific than the MTCSF, because the MTCSF typically includes some signal contamination that results from $\mathrm{T} 1$ weighting of the acquisition, but MTR requires twice the acquisition time and accurate coregistration of images. The MWF technique attempts to measure the quantity of myelin more directly by using a multiecho sequence to estimate the T2 parameter in each compartment (myelin, tissue, and CSF). However, some evidence suggests that the MTR is a more accurate measure of myelin quantity, because the MWF is sensitive to other cytoarchitectural features such as axon diameter, myelin thickness, and g-ratio. ${ }^{23}$ The MRS technique provides a measure of the absolute or relative concentrations of specific molecules within a single large voxel, usually $N$-acetyl aspartate (NAA), myo-inositol, choline, creatine, and lactate. In addition to the microstructural techniques, the expert panel identified functional MRI (fMRI) of the spinal cord as an important method that has the potential to quantify neurological function. fMRI typically relies on the concept of neurovascular coupling in which changes in neurological function produce corresponding changes in local blood flow and deoxyhemoglobin concentration, termed the blood oxygen level-dependent (BOLD) signal. fMRI studies use motor tasks or sensory stimuli in various study designs to generate neural activity, which is then measured as signal change in the image (with a latency termed the hemodynamic response), and provide an indirect but potentially powerful measure of neuronal activity and connectivity occurring within the spinal cord.

All of these emerging MRI techniques primarily generate quantitative outputs, setting them apart from conventional MRI that is more focused on anatomical imaging. Quantitative MRI can potentially provide imaging biomarkers that correlate well with neurological and functional impairment and reflect specific aberrant processes within the cord tissue. These techniques might also specifically show reversible and irreversible components of damage by differentiating between processes such as demyelination, axonal loss, and gray matter loss, which might enable better prognostication for patients with DCM. If these techniques are found to be highly sensitive for detecting early changes in the spinal cord, they could provide better diagnostic tools when there is uncertainty regarding diagnosis. They could also have a dramatic effect on surgical decision making in early or mild cases of DCM (e.g., by detecting progressive damage over repeated scans), in which there is currently debate regarding whether surgery is advantageous.

It is unfortunate that imaging the spinal cord with these advanced techniques is extremely challenging. All of these imaging methods were initially developed in the brain, but the spinal cord is far more difficult because of the inhomogeneity of the magnetic field at the interfaces between bone, IVDs, and CSF and because of the substantial motion of the cord caused by breathing and the cardiac cycle. ${ }^{107}$ Good-quality imaging using these techniques is a recent achievement made as a result of improvements in acquisition sequences and image processing to correct for motion and other artifacts.

\section{Studies Using Advanced MRI in DCM}

To date, a moderate number of studies have been completed using these new techniques in the context of DCM. A recent systematic review of the literature ${ }^{59}$ identified a total of 25 studies that used these techniques to study DCM; 22 used DTI, 3 used MRS, and 1 used MT (in combination with DTI). ${ }^{10,17,21,22,24,25,30,35,36,39,46,52,53,55,56,58,73,93,104,112 \text {, }}$ $116,124,125,129,136$ No clinical studies that used MWF or fMRI were identified. Among the identified DCM studies, the DTI metric fractional anisotropy (FA), a number that ranges from 0 for isotropic diffusion (same in all directions) to 1 for anisotropic (all in 1 direction), seemed to have the strongest results. Four studies reported the diagnostic accuracy of FA in detecting changes in subjects with DCM compared with that in healthy subjects; the sensitivity ranged from $72 \%$ to $95 \%$ and the specificity ranged from $50 \%$ to $100 \%$ in these studies. ${ }^{22,24,56,116}$ These values were consistently higher than the sensitivity and specificity of T2WI hyperintensity, although the gold standard for diagnosing DCM remains any sign of spinal cord compression (with or without T2WI hyperintensity) with accompanying clinical findings of myelopathy. The FA was also found to correlate well with clinical measures such as Japanese Orthopaedic Association (JOA) ${ }^{130}$ and modified JOA $(\mathrm{mJOA})^{14}$ scores in all 6 studies that reported these results, with Pearson R correlations of 0.57-0.64 and Spearman r correlations of $0.48-0.88 .^{24,30,39,55,58,124}$ Among the studies that attempted to identify the prognostic value of FA, only 1 of 3 found a correlation with follow-up JOA/mJOA scores, ${ }^{125}$ and that study reported an association between preoperative FA and improved postoperative JOA recovery ratios $(\mathrm{p}=0.03)$. Jones et al. ${ }^{39}$ identified a correlation between preoperative FA and postoperative neck disability index (Spearman $\mathrm{r}=-0.61, \mathrm{p}=0.04)$, but FA was not predictive of mJOA, Nurick scale, or 36-Item Short Form Health Survey (SF-36) scores. ${ }^{79,123}$ Other DTI metrics, such as mean diffusivity and radial diffusivity, have had less consistent results. . $2,56,116$ Two of 3 MRS studies found the ratio of NAA/creatine to be decreased significantly in terms of group differences compared with healthy subjects, ${ }^{35,112}$ but this metric did not correlate with mJOA 
scores in the 2 studies that performed this analysis..$^{35,93}$ Instead, Salamon et al ${ }^{93}$ found that only the choline/NAA ratio showed a significant correlation with $\mathrm{mJOA}$ scores (Pearson $\mathrm{R}=-0.45, \mathrm{p}<0.01$ ).

Overall, the current body of evidence demonstrates only modest clinical utility of these advanced MRI techniques, and the DTI metric FA has shown the strongest evidence in terms of correlation with symptoms. However, as these techniques continue to mature, it is highly likely that 1 or more advanced MRI techniques will transition successfully into clinical use.

\section{Future Directions for Advanced MRI}

For advanced MRI methods to achieve clinical relevance, 2 important conditions must be met. First, technical advances are necessary to improve overall image quality, which will require further improvements, such as to signalto-noise ratio (SNR) and spatial resolution, while image artifacts and distortions are minimized. These improvements are necessary for these MRI techniques to make accurate and reliable assessments to enable single-subject (patient) analysis. Second, even if these technological advances can be achieved, appropriate knowledge translation and development of clinically feasible protocols must be accomplished, which will require acceptable scan times and automated quantitative analysis tools. These techniques must be streamlined so that MRI technologists can perform the acquisitions comfortably and radiologists can incorporate quantitative analysis into their daily workflow, which will require a paradigm shift. A prerequisite to this shift is the development of robust automated tools that can perform all aspects of the quantitative analysis to avoid the painstaking analysis of manually drawing ROIs that is commonly performed in research studies. One such tool that has emerged recently, specifically designed for quantitative analysis spinal cord MRI data, is the Spinal Cord Toolbox (SCT), a free open-source toolkit. ${ }^{20}$ Looking ahead, well-designed translational studies of patients with DCM are needed to apply these powerful new techniques and analysis tools to identify clinical utility in terms of diagnostic accuracy, correlation with disability, and prediction of outcomes. It is unfortunate that these studies are difficult and costly to implement, require specialized expertise in imaging and spinal surgery, and require access to patients with DCM. Furthermore, novel MRI techniques are evolving continuously, and clinical studies (which take years to complete) tend to use acquisition methods that are out of date by the time of their completion. However, the potential benefits of these emerging tools are considerable and justify the large effort that is required to bring them to clinical use.

\section{Perspectives}

It is clear from this review that there are numerous ways in which a patient with DCM can be evaluated with MRI. However, despite the many methods available, there remains ongoing controversy regarding the association between the clinical diagnosis of cervical myelopathy and MRI findings. In particular, inconsistencies such as T2 hyperintensity, which can be seen occasionally in asymp- tomatic subjects but frequently are absent in patients with DCM, require further investigation. The subject is complicated further by a number of factors that prevent an evidence-based assessment of the body of literature, including 1) a lack of guidelines for the MRI assessment of patients with DCM; 2) a lack of physiological MRI parameters, such as canal size, that can be used as references to objectively differentiate pathological findings from normal findings; 3) a lack of longitudinal studies that evaluate the natural history of DCM via MRI; and 4) no uniform methods for classifying frequently used terminology, such as spondylosis.

To begin to address these knowledge gaps, this review was undertaken to provide a comprehensive review of the various MRI measurement techniques at the disposal of clinicians and researchers. Going forward, we suggest that evidence-based guidelines be established with the intentions of providing a more reproducible approach to image analysis, improving the assessment of disease in individual patients, and building a standard of analysis for clinical research studies while acknowledging that MRI acquisition and analysis techniques will continue to evolve.

The use of MRI has a number of noteworthy limitations, however, that should be discussed briefly. The costs remain substantially higher than those of basic imaging modalities, and the occurrence of artifacts, such as motion and truncation (Gibbs) artifacts, can result in degraded images. Technical differences in image acquisitions and differences in magnet strengths can also affect the quality of images and therefore the accuracy of measurements. Last, conventional MRIs are obtained with the patient in a static, supine, and non-weight-bearing position, which affects the assessment of patients with DCM in the following ways: 1) it is unclear if optimal sagittal alignment measurements can be obtained, 2) movement-dependent spinal compression can be missed, and 3) changes to the degree of stenosis or cord compression during weight-bearing of the head can be missed. However, the static and positionbased limitations might be overcome in the future with the emergence of upright and flexion/extension MRI technologies.

The greater accessibility of MRI has not only enabled clear inspection of soft-tissue structures in patients with DCM but also reduced the necessity for exposure to ionizing radiation. It is clear, however, that radiography and CT will still play a role, because they are readily available and accessible in emergency settings, can be applied when contraindications to MRI exist (e.g., implanted devices such as cardiac pacemakers), and can still provide important measurements as they relate to bony structures.

\section{Conclusions}

Numerous techniques are available for assessing patients with DCM, and many grading systems have been proposed over the years. Although some measurement techniques have been well recognized and are widely used, many other techniques have been reported only infrequently in the literature. The reason for this is unclear, but the lack of a collated review of measurement techniques available to medical professionals and researchers 
may be a contributory factor. Ultimately, the standardization of measurement techniques would allow for better comparisons of research findings and clearer evidence for clinical utility. Future research in this area should focus on the knowledge gaps that have emerged through this review, and the eventual objective should be to create MRI assessment guidelines that encompass a broad set of reliable and valid measurement techniques for assessing patients with DCM.

\section{References}

1. Aguila LA, Piraino DW, Modic MT, Dudley AW, Duchesneau PM, Weinstein MA: The intranuclear cleft of the intervertebral disk: magnetic resonance imaging. Radiology 155: $155-158,1985$

2. Al-Mefty O, Harkey LH, Middleton TH, Smith RR, Fox JL: Myelopathic cervical spondylotic lesions demonstrated by magnetic resonance imaging. J Neurosurg 68:217-222, 1988

3. Alafifi T, Kern R, Fehlings M: Clinical and MRI predictors of outcome after surgical intervention for cervical spondylotic myelopathy. J Neuroimaging 17:315-322, 2007

4. Ames CP, Blondel B, Scheer JK, Schwab FJ, Le Huec JC, Massicotte EM, et al: Cervical radiographical alignment: comprehensive assessment techniques and potential importance in cervical myelopathy. Spine (Phila Pa 1976) 38 (22 Suppl 1):S149-S160, 2013

5. Arvin B, Kalsi-Ryan S, Karpova A, Mercier D, Furlan JC, Massicotte EM, et al: Postoperative magnetic resonance imaging can predict neurological recovery after surgery for cervical spondylotic myelopathy: a prospective study with blinded assessments. Neurosurgery 69:362-368, 2011

6. Arvin B, Kalsi-Ryan S, Mercier D, Furlan JC, Massicotte EM, Fehlings MG: Preoperative magnetic resonance imaging is associated with baseline neurological status and can predict postoperative recovery in patients with cervical spondylotic myelopathy. Spine (Phila Pa 1976) 38:11701176, 2013

7. Avadhani A, Rajasekaran S, Shetty AP: Comparison of prognostic value of different MRI classifications of signal intensity change in cervical spondylotic myelopathy. Spine J 10:475-485, 2010

8. Aydoğ ST, Türbedar E, Demirel AH, Tetik O, Akin A, Doral MN: Cervical and lumbar spinal changes diagnosed in four-view radiographs of 732 military pilots. Aviat Space Environ Med 75:154-157, 2004

9. Bajwa NS, Toy JO, Young EY, Ahn NU: Establishment of parameters for congenital stenosis of the cervical spine: an anatomic descriptive analysis of 1,066 cadaveric specimens. Eur Spine J 21:2467-2474, 2012

10. Banaszek A, Bladowska J, Szewczyk P, Podgórski P, Sąsiadek M: Usefulness of diffusion tensor MR imaging in the assessment of intramedullary changes of the cervical spinal cord in different stages of degenerative spine disease. Eur Spine J 23:1523-1530, 2014

11. Baptiste DC, Fehlings MG: Pathophysiology of cervical myelopathy. Spine J 6 (6 Suppl):190S-197S, 2006

12. Battié MC, Videman T, Gill K, Moneta GB, Nyman R, Kaprio J, et al: 1991 Volvo Award in clinical sciences. Smoking and lumbar intervertebral disc degeneration: an MRI study of identical twins. Spine (Phila Pa 1976) 16: 1015-1021, 1991

13. Batzdorf U, Batzdorff A: Analysis of cervical spine curvature in patients with cervical spondylosis. Neurosurgery 22:827-836, 1988

14. Benzel EC, Lancon J, Kesterson L, Hadden T: Cervical laminectomy and dentate ligament section for cervical spondylotic myelopathy. J Spinal Disord 4:286-295, 1991
15. Bernstein P, Hentschel S, Platzek I, Zwingenberger S, Weigel $S$, Hühne $S$, et al: The assessment of the postoperative spinal alignment: MRI adds up on accuracy. Eur Spine J 21:733-738, 2012

16. Boet R, Chan YL, King A, Mok CT, Poon WS: Contrast enhancement of the spinal cord in a patient with cervical spondylotic myelopathy. J Clin Neurosci 11:512-514, 2004

17. Budzik JF, Balbi V, Le Thuc V, Duhamel A, Assaker R, Cotten A: Diffusion tensor imaging and fibre tracking in cervical spondylotic myelopathy. Eur Radiol 21:426-433, 2011

18. Chatley A, Kumar R, Jain VK, Behari S, Sahu RN: Effect of spinal cord signal intensity changes on clinical outcome after surgery for cervical spondylotic myelopathy. J Neurosurg Spine 11:562-567, 2009

19. Chen CJ, Lyu RK, Lee ST, Wong YC, Wang LJ: Intramedullary high signal intensity on T2-weighted MR images in cervical spondylotic myelopathy: prediction of prognosis with type of intensity. Radiology 221:789-794, 2001

20. Cohen-Adad J, De Leener B, Benhamou M, Lévy S, Touati J, Cadotte D, et al: Spinal Cord Toolbox: an open-source framework for processing spinal cord MRI data. Presented at the 20th Annual Meeting of the Organization for Human Brain Mapping, Hamburg, Germany, 2014 (Poster) (https://www.researchgate.net/ publication/284653428_Spinal_Cord_Toolbox_an_opensource_framework_for_processing_spinal_cord_MRI_data) [Accessed April 5, 2016]

21. Cui JL, Li X, Chan TY, Mak KC, Luk KD, Hu Y: Quantitative assessment of column-specific degeneration in cervical spondylotic myelopathy based on diffusion tensor tractography. Eur Spine J 24:41-47, 2015

22. Demir A, Ries M, Moonen CT, Vital JM, Dehais J, Arne P, et al: Diffusion-weighted MR imaging with apparent diffusion coefficient and apparent diffusion tensor maps in cervical spondylotic myelopathy. Radiology 229:37-43, 2003

23. Dula AN, Gochberg DF, Valentine HL, Valentine WM, Does MD: Multiexponential T2, magnetization transfer, and quantitative histology in white matter tracts of rat spinal cord. Magn Reson Med 63:902-909, 2010

24. Ellingson BM, Salamon N, Grinstead JW, Holly LT: Diffusion tensor imaging predicts functional impairment in mild-to-moderate cervical spondylotic myelopathy. Spine J 14:2589-2597, 2014

25. Facon D, Ozanne A, Fillard P, Lepeintre JF, TournouxFacon C, Ducreux D: MR diffusion tensor imaging and fiber tracking in spinal cord compression. AJNR Am J Neuroradiol 26:1587-1594, 2005

26. Fehlings MG, Rao SC, Tator CH, Skaf G, Arnold P, Benzel $\mathrm{E}$, et al: The optimal radiologic method for assessing spinal canal compromise and cord compression in patients with cervical spinal cord injury. Part II: Results of a multicenter study. Spine (Phila Pa 1976) 24:605-613, 1999

27. Flanagan EP, Krecke KN, Marsh RW, Giannini C, Keegan BM, Weinshenker BG: Specific pattern of gadolinium enhancement in spondylotic myelopathy. Ann Neurol 76:54-65, 2014

28. Fujiwara K, Yonenobu K, Hiroshima K, Ebara S, Yamashita $\mathrm{K}$, Ono K: Morphometry of the cervical spinal cord and its relation to pathology in cases with compression myelopathy. Spine (Phila Pa 1976) 13:1212-1216, 1988

29. Galbusera F, van Rijsbergen M, Ito K, Huyghe JM, BraydaBruno M, Wilke HJ: Ageing and degenerative changes of the intervertebral disc and their impact on spinal flexibility. Eur Spine J 23 (Suppl 3):S324-S332, 2014

30. Gao SJ, Yuan X, Jiang XY, Liu XX, Liu XP, Wang YF, et al: Correlation study of 3T-MR-DTI measurements and 
clinical symptoms of cervical spondylotic myelopathy. Eur J Radiol 82:1940-1945, 2013

31. Guo JJ, Luk KD, Karppinen J, Yang H, Cheung KM: Prevalence, distribution, and morphology of ossification of the ligamentum flavum: a population study of one thousand seven hundred thirty-six magnetic resonance imaging scans. Spine (Phila Pa 1976) 35:51-56, 2010

32. Hamanishi C, Kawabata T, Yosii T, Tanaka S: Schmorl's nodes on magnetic resonance imaging. Their incidence and clinical relevance. Spine (Phila Pa 1976) 19:450-453, 1994

33. Harrop JS, Naroji S, Maltenfort M, Anderson DG, Albert T, Ratliff JK, et al: Cervical myelopathy: a clinical and radiographic evaluation and correlation to cervical spondylotic myelopathy. Spine (Phila Pa 1976) 35:620-624, 2010

34. Hayashi T, Wang JC, Suzuki A, Takahashi S, Scott TP, Phan K, et al: Risk factors for missed dynamic canal stenosis in the cervical spine. Spine (Phila Pa 1976) 39:812819,2014

35. Holly LT, Freitas B, McArthur DL, Salamon N: Proton magnetic resonance spectroscopy to evaluate spinal cord axonal injury in cervical spondylotic myelopathy. $\mathbf{J}$ Neurosurg Spine 10:194-200, 2009

36. Hori M, Fukunaga I, Masutani Y, Taoka T, Kamagata K, Suzuki Y, et al: Visualizing non-Gaussian diffusion: clinical application of q-space imaging and diffusional kurtosis imaging of the brain and spine. Magn Reson Med Sci 11:221-233, 2012

37. Inamasu J, Guiot BH, Sachs DC: Ossification of the posterior longitudinal ligament: an update on its biology, epidemiology, and natural history. Neurosurgery 58:1027-1039, 2006

38. Ishikawa M, Matsumoto M, Fujimura Y, Chiba K, Toyama Y: Changes of cervical spinal cord and cervical spinal canal with age in asymptomatic subjects. Spinal Cord 41:159 163,2003

39. Jones JG, Cen SY, Lebel RM, Hsieh PC, Law M: Diffusion tensor imaging correlates with the clinical assessment of disease severity in cervical spondylotic myelopathy and predicts outcome following surgery. AJNR Am J Neuroradiol 34:471-478, 2013

40. Kang Y, Lee JW, Koh YH, Hur S, Kim SJ, Chai JW, et al: New MRI grading system for the cervical canal stenosis. AJR Am J Roentgenol 197:W134-W140, 2011

41. Karpova A, Arun R, Cadotte DW, Davis AM, Kulkarni AV, O'Higgins M, et al: Assessment of spinal cord compression by magnetic resonance imaging - can it predict surgical outcomes in degenerative compressive myelopathy? A systematic review. Spine (Phila Pa 1976) 38:1409-1421, 2013

42. Karpova A, Arun R, Kalsi-Ryan S, Massicotte EM, Kopjar B, Fehlings MG: Do quantitative magnetic resonance imaging parameters correlate with the clinical presentation and functional outcomes after surgery in cervical spondylotic myelopathy? A prospective multicenter study. Spine (Phila Pa 1976) 39:1488-1497, 2014

43. Kato F, Yukawa Y, Suda K, Yamagata M, Ueta T: Normal morphology, age-related changes and abnormal findings of the cervical spine. Part II: Magnetic resonance imaging of over 1,200 asymptomatic subjects. Eur Spine J 21:14991507,2012

44. Kawasaki M, Tani T, Ushida T, Ishida K: Anterolisthesis and retrolisthesis of the cervical spine in cervical spondylotic myelopathy in the elderly. J Orthop Sci 12:207-213, 2007

45. Kellgren JH, Lawrence JS: Atlas of Standard Radiographs: The Epidemiology of Chronic Rheumatism. Oxford: Blackwell Scientific, 1963, Vol 2

46. Kerkovský M, Bednarík J, Dušek L, Sprláková-Puková A, Urbánek I, Mechl M, et al: Magnetic resonance diffusion tensor imaging in patients with cervical spondylotic spinal cord compression: correlations between clinical and electrophysiological findings. Spine (Phila Pa 1976) 37:48-56, 2012

47. Kishiya M, Sawada T, Kanemaru K, Kudo H, Numasawa T, Yokoyama T, et al: A functional RNAi screen for Runx2regulated genes associated with ectopic bone formation in human spinal ligaments. J Pharmacol Sci 106:404-414, 2008

48. Kong Q, Ma X, Li F, Guo Z, Qi Q, Li W, et al: COL6A1 polymorphisms associated with ossification of the ligamentum flavum and ossification of the posterior longitudinal ligament. Spine (Phila Pa 1976) 32:2834-2838, 2007

49. Lane NE, Nevitt MC, Genant HK, Hochberg MC: Reliability of new indices of radiographic osteoarthritis of the hand and hip and lumbar disc degeneration. $\mathbf{J}$ Rheumatol 20:1911-1918, 1993

50. Lehto IJ, Tertti MO, Komu ME, Paajanen HE, Tuominen J, Kormano MJ: Age-related MRI changes at $0.1 \mathrm{~T}$ in cervical discs in asymptomatic subjects. Neuroradiology 36:49-53, 1994

51. Li F, Chen Z, Zhang F, Shen H, Hou T: A meta-analysis showing that high signal intensity on T2-weighted MRI is associated with poor prognosis for patients with cervical spondylotic myelopathy. J Clin Neurosci 18:1592-1595, 2011

52. Li X, Cui JL, Mak KC, Luk KD, Hu Y: Potential use of diffusion tensor imaging in level diagnosis of multilevel cervical spondylotic myelopathy. Spine (Phila Pa 1976) 39:E615-E622, 2014

53. Lindberg PG, Feydy A, Sanchez K, Rannou F, Maier MA: Measures of spinal canal stenosis and relationship to spinal cord structure in patients with cervical spondylosis. $\mathbf{J}$ Neuroradiol 39:236-242, 2012

54. Lipson SJ, Fox DA, Sosman JL: Symptomatic intravertebral disc herniation (Schmorl's node) in the cervical spine. Ann Rheum Dis 44:857-859, 1985

55. Maki S, Koda M, Ota M, Oikawa Y, Kamiya K, Inada T, et al: Reduced field-of-view diffusion tensor imaging of the spinal cord shows motor dysfunction of the lower extremities in patients with cervical compression myelopathy. Spine (Phila Pa 1976) [epub ahead of print], 2015

56. Mamata H, Jolesz FA, Maier SE: Apparent diffusion coefficient and fractional anisotropy in spinal cord: age and cervical spondylosis-related changes. J Magn Reson Imaging 22:38-43, 2005

57. Mann E, Peterson CK, Hodler J: Degenerative marrow (Modic) changes on cervical spine magnetic resonance imaging scans: prevalence, inter- and intra-examiner reliability and link to disc herniation. Spine (Phila Pa 1976) 36:1081-1085, 2011

58. Martin AR, Aleksanderek I, Cohen-Adad J, Cadotte DW, Kalsi-Ryan S, Nugaeva N, et al: Next-generation MRI of the human spinal cord: a prospective longitudinal study in cervical spondylotic myelopathy (CSM) to develop quantitative imaging biomarkers, in Congress of Neurological Surgeons Annual Meeting, New Orleans, LA, 2015 (Poster) (http://2015.cns.org/posterbrowser.aspx) [Accessed April 5, 2016]

59. Martin AR, Aleksanderek I, Cohen-Adad J, Tarmohamed Z, Tetreault L, Smith N, et al: Translating state-of-the-art spinal cord MRI techniques to clinical use: A systematic review of clinical studies utilizing DTI, MT, MWF, MRS, and fMRI. Neuroimage Clin 10:192-238, 2015

60. Mastronardi L, Elsawaf A, Roperto R, Bozzao A, Caroli M, Ferrante M, et al: Prognostic relevance of the postoperative evolution of intramedullary spinal cord changes in signal intensity on magnetic resonance imaging after anterior decompression for cervical spondylotic myelopathy. J Neurosurg Spine 7:615-622, 2007 
61. Matsumoto M, Fujimura Y, Suzuki N, Nishi Y, Nakamura M, Yabe Y, et al: MRI of cervical intervertebral discs in asymptomatic subjects. J Bone Joint Surg Br 80:19-24, 1998

62. Mattei TA, Rehman AA: Schmorl's nodes: current pathophysiological, diagnostic, and therapeutic paradigms. Neurosurg Rev 37:39-46, 2014

63. Meyerding H: Spondylolisthesis. Surg Gynecol Obstet 54: 371-377, 1932

64. Miyasaka K, Kaneda K, Sato S, Iwasaki Y, Abe S, Takei H, et al: Myelopathy due to ossification or calcification of the ligamentum flavum: radiologic and histologic evaluations. AJNR Am J Neuroradiol 4:629-632, 1983

65. Miyazaki M, Hong SW, Yoon SH, Morishita Y, Wang JC: Reliability of a magnetic resonance imaging-based grading system for cervical intervertebral disc degeneration. $\mathbf{J}$ Spinal Disord Tech 21:288-292, 2008

66. Mizuno J, Nakagawa H, Hashizume Y: Analysis of hypertrophy of the posterior longitudinal ligament of the cervical spine, on the basis of clinical and experimental studies. Neurosurgery 49:1091-1098, 2001

67. Modic MT, Steinberg PM, Ross JS, Masaryk TJ, Carter JR: Degenerative disk disease: assessment of changes in vertebral body marrow with MR imaging. Radiology 166:193199,1988

68. Mohanty C, Massicotte EM, Fehlings MG, Shamji MF: Association of preoperative cervical spine alignment with spinal cord magnetic resonance imaging hyperintensity and myelopathy severity: analysis of a series of 124 cases. Spine (Phila Pa 1976) 40:11-16, 2015

69. Morio Y, Teshima R, Nagashima H, Nawata K, Yamasaki D, Nanjo Y: Correlation between operative outcomes of cervical compression myelopathy and MRI of the spinal cord. Spine (Phila Pa 1976) 26:1238-1245, 2001

70. Morio Y, Yamamoto K, Kuranobu K, Murata M, Tuda K: Does increased signal intensity of the spinal cord on MR images due to cervical myelopathy predict prognosis? Arch Orthop Trauma Surg 113:254-259, 1994

71. Muhle C, Metzner J, Weinert D, Falliner A, Brinkmann $\mathrm{G}$, Mehdorn MH, et al: Classification system based on kinematic MR imaging in cervical spondylitic myelopathy. AJNR Am J Neuroradiol 19:1763-1771, 1998

72. Nagata K, Yoshimura N, Hashizume H, Muraki S, Ishimoto $\mathrm{Y}$, Yamada $\mathrm{H}$, et al: The prevalence of cervical myelopathy among subjects with narrow cervical spinal canal in a population-based magnetic resonance imaging study: the Wakayama Spine Study. Spine J 14:2811-2817, 2014

73. Nakamura M, Fujiyoshi K, Tsuji O, Konomi T, Hosogane $\mathrm{N}$, Watanabe K, et al: Clinical significance of diffusion tensor tractography as a predictor of functional recovery after laminoplasty in patients with cervical compressive myelopathy. J Neurosurg Spine 17:147-152, 2012

74. Nakashima H, Yukawa Y, Ito K, Machino M, Kanbara S, Morita D, et al: Prediction of lower limb functional recovery after laminoplasty for cervical myelopathy: focusing on the 10-s step test. Eur Spine J 21:1389-1395, 2012

75. Nakashima H, Yukawa Y, Suda K, Yamagata M, Ueta T, Kato F: Cervical disc protrusion correlates with the severity of cervical disc degeneration: a cross-sectional study of 1,211 relatively healthy volunteers. Spine (Phila Pa 1976) 40:E774-E779, 2015

76. Northover JR, Wild JB, Braybrooke J, Blanco J: The epidemiology of cervical spondylotic myelopathy. Skeletal Radiol 41: 1543-1546, 2012

77. Nouri A, Tetreault L, Singh A, Karadimas SK, Fehlings MG: Degenerative cervical myelopathy: epidemiology, genetics, and pathogenesis. Spine (Phila Pa 1976) 40:E675-E693, 2015

78. Nouri A, Tetreault L, Zamorano JJ, Dalzell K, Davis AM,
Mikulis D, et al: Role of magnetic resonance imaging in predicting surgical outcome in patients with cervical spondylotic myelopathy. Spine (Phila Pa 1976) 40:171-178, 2015

79. Nurick S: The pathogenesis of the spinal cord disorder associated with cervical spondylosis. Brain 95:87-100, 1972

80. Ohara A, Miyamoto K, Naganawa T, Matsumoto K, Shimizu K: Reliabilities of and correlations among five standard methods of assessing the sagittal alignment of the cervical spine. Spine (Phila Pa 1976) 31:2585-2592, 2006

81. Okada E, Matsumoto M, Fujiwara H, Toyama Y: Disc degeneration of cervical spine on MRI in patients with lumbar disc herniation: comparison study with asymptomatic volunteers. Eur Spine J 20:585-591, 2011

82. Okada Y, Ikata T, Yamada H, Sakamoto R, Katoh S: Magnetic resonance imaging study on the results of surgery for cervical compression myelopathy. Spine (Phila Pa 1976) 18:2024-2029, 1993

83. Ono K, Yonenobu K, Miyamoto S, Okada K: Pathology of ossification of the posterior longitudinal ligament and ligamentum flavum. Clin Orthop Relat Res (359): 18-26, 1999

84. Oshima Y, Seichi A, Takeshita K, Chikuda H, Ono T, Baba $\mathrm{S}$, et al: Natural course and prognostic factors in patients with mild cervical spondylotic myelopathy with increased signal intensity on T2-weighted magnetic resonance imaging. Spine (Phila Pa 1976) 37:1909-1913, 2012

85. Ozawa H, Sato T, Hyodo H, Ishii Y, Morozumi N, Koizumi $\mathrm{Y}$, et al: Clinical significance of intramedullary Gd-DTPA enhancement in cervical myelopathy. Spinal Cord 48:415422, 2010

86. Park JY, Chin DK, Kim KS, Cho YE: Thoracic ligament ossification in patients with cervical ossification of the posterior longitudinal ligaments: tandem ossification in the cervical and thoracic spine. Spine (Phila Pa 1976) 33:E407E410, 2008

87. Pavlov H, Torg JS, Robie B, Jahre C: Cervical spinal stenosis: determination with vertebral body ratio method. Radiology 164:771-775, 1987

88. Peterson CK, Humphreys BK, Pringle TC: Prevalence of Modic degenerative marrow changes in the cervical spine. $\mathbf{J}$ Manipulative Physiol Ther 30:5-10, 2007

89. Pfirrmann CW, Metzdorf A, Zanetti M, Hodler J, Boos N: Magnetic resonance classification of lumbar intervertebral disc degeneration. Spine (Phila Pa 1976) 26:1873-1878, 2001

90. Prasad SS, O’Malley M, Caplan M, Shackleford IM, Pydisetty RK: MRI measurements of the cervical spine and their correlation to Pavlov's ratio. Spine (Phila Pa 1976) 28:1263-1268, 2003

91. Rhee JM, Heflin JA, Hamasaki T, Freedman B: Prevalence of physical signs in cervical myelopathy: a prospective, controlled study. Spine (Phila Pa 1976) 34:890-895, 2009

92. Ruangchainikom M, Daubs MD, Suzuki A, Hayashi T, Weintraub G, Lee CJ, et al: Effect of cervical kyphotic deformity type on the motion characteristics and dynamic spinal cord compression. Spine (Phila Pa 1976) 39:932938, 2014

93. Salamon N, Ellingson BM, Nagarajan R, Gebara N, Thomas A, Holly LT: Proton magnetic resonance spectroscopy of human cervical spondylosis at 3T. Spinal Cord 51:558563,2013

94. Salem HM, Salem KM, Burget F, Bommireddy R, Klezl Z: Cervical spondylotic myelopathy: the prediction of outcome following surgical intervention in 93 patients using T1- and T2-weighted MRI scans. Eur Spine J 24:2930-2935, 2015

95. Schiebler ML, Camerino VJ, Fallon MD, Zlatkin MB, Grenier N, Kressel HY: In vivo and ex vivo magnetic resonance imaging evaluation of early disc degeneration with histopathologic correlation. Spine (Phila Pa 1976) 16:635640,1991 
96. Schmitz A, Jaeger UE, Koenig R, Kandyba J, Wagner UA, Giesecke J, et al: A new MRI technique for imaging scoliosis in the sagittal plane. Eur Spine J 10:114-117, 2001

97. Schneiderman G, Flannigan B, Kingston S, Thomas J, Dillin WH, Watkins RG: Magnetic resonance imaging in the diagnosis of disc degeneration: correlation with discography. Spine (Phila Pa 1976) 12:276-281, 1987

98. Sether LA, Yu S, Haughton VM, Fischer ME: Intervertebral disk: normal age-related changes in MR signal intensity. Radiology 177:385-388, 1990

99. Setzer M, Hermann E, Seifert V, Marquardt G: Apolipoprotein E gene polymorphism and the risk of cervical myelopathy in patients with chronic spinal cord compression. Spine (Phila Pa 1976) 33:497-502, 2008

100. Sherman JL, Nassaux PY, Citrin CM: Measurements of the normal cervical spinal cord on MR imaging. AJNR Am J Neuroradiol 11:369-372, 1990

101. Shimomura T, Sumi M, Nishida K, Maeno K, Tadokoro K, Miyamoto H, et al: Prognostic factors for deterioration of patients with cervical spondylotic myelopathy after nonsurgical treatment. Spine (Phila Pa 1976) 32:2474-2479, 2007

102. Shin JJ, Jin BH, Kim KS, Cho YE, Cho WH: Intramedullary high signal intensity and neurological status as prognostic factors in cervical spondylotic myelopathy. Acta Neurochir (Wien) 152:1687-1694, 2010

103. Singh A, Crockard HA, Platts A, Stevens J: Clinical and radiological correlates of severity and surgery-related outcome in cervical spondylosis. J Neurosurg 94 (2 Suppl):189-198, 2001

104. Song T, Chen WJ, Yang B, Zhao HP, Huang JW, Cai MJ, et al: Diffusion tensor imaging in the cervical spinal cord. Eur Spine J 20:422-428, 2011

105. Stapleton CJ, Pham MH, Attenello FJ, Hsieh PC: Ossification of the posterior longitudinal ligament: genetics and pathophysiology. Neurosurg Focus 30(3):E6, 2011

106. Street J, Lenehan B, Albietz J, Bishop P, Dvorak M, Fisher $\mathrm{C}$ : Intraobserver and interobserver reliability of measures of kyphosis in thoracolumbar fractures. Spine J 9:464-469, 2009

107. Stroman PW, Wheeler-Kingshott C, Bacon M, Schwab JM, Bosma R, Brooks J, et al: The current state-of-the-art of spinal cord imaging: methods. Neuroimage 84:1070-1081, 2014

108. Sugimura H, Kakitsubata Y, Suzuki Y, Kakitsubata S, Tamura S, Uwada O, et al: MRI of ossification of ligamentum flavum. J Comput Assist Tomogr 16:73-76, 1992

109. Suleiman LI, Bhatt SA, Parrish TB, Patel AA: Imaging modalities and tests for cervical myelopathy. Semin Spine Surg 26:68-72, 2014

110. Suri A, Chabbra RP, Mehta VS, Gaikwad S, Pandey RM: Effect of intramedullary signal changes on the surgical outcome of patients with cervical spondylotic myelopathy. Spine J 3:33-45, 2003

111. Suzuki A, Daubs MD, Inoue H, Hayashi T, Aghdasi B, Montgomery SR, et al: Prevalence and motion characteristics of degenerative cervical spondylolisthesis in the symptomatic adult. Spine (Phila Pa 1976) 38:E1115-E1120, 2013

112. Taha Ali TF, Badawy AE: Feasibility of ${ }^{1} \mathrm{H}-\mathrm{MR}$ spectroscopy in evaluation of cervical spondylotic myelopathy. Egypt J Radiol Nucl Med 44:93-99, 2013

113. Takahashi M, Yamashita Y, Sakamoto Y, Kojima R: Chronic cervical cord compression: clinical significance of increased signal intensity on MR images. Radiology 173:219-224, 1989

114. Tetreault LA, Dettori JR, Wilson JR, Singh A, Nouri A, Fehlings MG, et al: Systematic review of magnetic resonance imaging characteristics that affect treatment decision making and predict clinical outcome in patients with cervi- cal spondylotic myelopathy. Spine (Phila Pa 1976) 38 (22 Suppl 1):S89-S110, 2013

115. Uchida K, Nakajima H, Sato R, Kokubo Y, Yayama T, Kobayashi S, et al: Multivariate analysis of the neurological outcome of surgery for cervical compressive myelopathy. $\mathbf{J}$ Orthop Sci 10:564-573, 2005

116. Uda T, Takami T, Tsuyuguchi N, Sakamoto S, Yamagata T, Ikeda $\mathrm{H}$, et al: Assessment of cervical spondylotic myelopathy using diffusion tensor magnetic resonance imaging parameter at 3.0 tesla. Spine (Phila Pa 1976) 38:407-414, 2013

117. van Goethem JWM, van den Hauwe L, Parizel PM: Spinal Imaging: Diagnostic Imaging of the Spine and Spinal Cord, ed 1. Berlin: Springer, 2007

118. Vedantam A, Jonathan A, Rajshekhar V: Association of magnetic resonance imaging signal changes and outcome prediction after surgery for cervical spondylotic myelopathy. J Neurosurg Spine 15:660-666, 2011

119. Vedantam A, Rajshekhar V: Change in morphology of intramedullary T2-weighted increased signal intensity after anterior decompressive surgery for cervical spondylotic myelopathy. Spine (Phila Pa 1976) 39:1458-1462, 2014

120. Vedantam A, Rajshekhar V: Does the type of T2-weighted hyperintensity influence surgical outcome in patients with cervical spondylotic myelopathy? A review. Eur Spine J 22:96-106, 2013

121. Wada E, Yonenobu K, Suzuki S, Kanazawa A, Ochi T: Can intramedullary signal change on magnetic resonance imaging predict surgical outcome in cervical spondylotic myelopathy? Spine (Phila Pa 1976) 24:455-462, 1999

122. Wang LF, Zhang YZ, Shen Y, Su YL, Xu JX, Ding WY, et al: Using the T2-weighted magnetic resonance imaging signal intensity ratio and clinical manifestations to assess the prognosis of patients with cervical ossification of the posterior longitudinal ligament. J Neurosurg Spine 13:319-323, 2010

123. Ware JE Jr, Sherbourne CD: The MOS 36-Item Short Form Health Survey (SF-36). I. Conceptual framework and item selection. Med Care 30:473-483, 1992

124. Wen CY, Cui JL, Liu HS, Mak KC, Cheung WY, Luk KD, et al: Is diffusion anisotropy a biomarker for disease severity and surgical prognosis of cervical spondylotic myelopathy? Radiology 270:197-204, 2014

125. Wen CY, Cui JL, Mak KC, Luk KD, Hu Y: Diffusion tensor imaging of somatosensory tract in cervical spondylotic myelopathy and its link with electrophysiological evaluation. Spine J 14:1493-1500, 2014

126. Wessberg P, Danielson BI, Willén J: Comparison of Cobb angles in idiopathic scoliosis on standing radiographs and supine axially loaded MRI. Spine (Phila Pa 1976) 31:3039-3044, 2006

127. Williams FM, Manek NJ, Sambrook PN, Spector TD, Macgregor AJ: Schmorl's nodes: common, highly heritable, and related to lumbar disc disease. Arthritis Rheum 57:855-860, 2007

128. Wong JJ, Leung OC, Yuen MK: Questionable adequacy of magnetic resonance for the detection of ossification of the posterior longitudinal ligament of the cervical spine. Hong Kong J Radiol 14:78-83, 2011

129. Xiangshui M, Xiangjun C, Xiaoming Z, Qingshi Z, Yi C, Chuanqiang Q, et al: $3 \mathrm{~T}$ magnetic resonance diffusion tensor imaging and fibre tracking in cervical myelopathy. Clin Radiol 65:465-473, 2010

130. Yamauchi Y, Hirabayashi K: Scoring system (17-2) for cervical myelopathy (Japanese Orthopaedic Association). J Jpn Orthop Assoc 68:490-503, 1994

131. Yoshimatsu H, Nagata K, Goto H, Sonoda K, Ando N, Imoto $\mathrm{H}$, et al: Conservative treatment for cervical spondylotic myelopathy. Prediction of treatment effects by multivariate analysis. Spine J 1:269-273, 2001 
132. You JY, Lee JW, Lee E, Lee GY, Yeom JS, Kang HS: MR classification system based on axial images for cervical compressive myelopathy. Radiology 276:553-561, 2015

133. Zhang P, Shen Y, Zhang YZ, Ding WY, Wang LF: Significance of increased signal intensity on MRI in prognosis after surgical intervention for cervical spondylotic myelopathy. J Clin Neurosci 18:1080-1083, 2011

134. Zhang YH, Zhao CQ, Jiang LS, Chen XD, Dai LY: Modic changes: a systematic review of the literature. Eur Spine J 17:1289-1299, 2008

135. Zhang YZ, Shen Y, Wang LF, Ding WY, Xu JX, He J: Magnetic resonance T2 image signal intensity ratio and clinical manifestation predict prognosis after surgical intervention for cervical spondylotic myelopathy. Spine (Phila Pa 1976) 35:E396-E399, 2010

136. Zhou F, Gong H, Liu X, Wu L, Luk KD, Hu Y: Increased low-frequency oscillation amplitude of sensorimotor cortex associated with the severity of structural impairment in cervical myelopathy. PLoS One 9:e104442, 2014

\section{Disclosures}

The authors report no conflict of interest concerning the materials or methods used in this study or the findings specified in this paper.

\section{Author Contributions}

Conception and design: Nouri, Fehlings. Acquisition of data: all authors. Analysis and interpretation of data: all authors. Drafting the article: all authors. Critically revising the article: all authors. Reviewed submitted version of manuscript: all authors. Statistical analysis: Nouri, Fehlings, Mikulis.

\section{Correspondence}

Michael G. Fehlings, Department of Neurosurgery, University of Toronto, 399 Bathurst St., Toronto Western Hospital, Toronto, ON M5T 2S8, Canada. email: michael.fehlings@uhn.ca. 